\title{
Phenotypical Differences in Connective Tissue Cells Emerging from Microvascular Pericytes in Response to Overexpression of PDGF-B and TGF- $\beta 1$ in Normal Skin in Vivo
}

\author{
Alejandro Rodriguez, ${ }^{*}$ Tomas Friman, ${ }^{*}$ Marcin Kowanetz, ${ }^{\dagger}$ Tijs van Wieringen, ${ }^{*}$ Renata Gustafsson, ${ }^{*}$ and Christian Sundberg ${ }^{* \ddagger}$
}

From the Departments of Medical Biochemistry and Microbiology* and Women and Children’s Health, ${ }^{\ddagger}$ Uppsala University, Uppsala, Sweden; and Genentech Inc., ${ }^{\dagger}$ South San Francisco, California

Accepted for publication January 29, 2013.

Address correspondence to Christian Sundberg, M.D., Ph.D., Department of Medical Biochemistry and Microbiology, Box 582, Biomedical Center, S-75123, Uppsala, Sweden. E-mail: christian. sundberg@imbim.uu.se.

\begin{abstract}
Fibrosis is a deleterious consequence of chronic inflammation in a number of human pathologies ultimately leading to organ dysfunction and failure. Two growth factors that are important in blood vessel physiology and tissue fibrosis, platelet-derived growth factor (PDGF)-B and transforming growth factor (TGF)- $\beta 1$, were investigated. Adenoviral vectors were used to induce transient overexpression of these growth factors in mouse skin. Changes in tissue structure and protein and mRNA expressions were investigated. Both PDGF-B and TGF- $\beta 1$ could initiate but neither could sustain angiogenesis. Instead, vascular regression was observed. Overexpression of both TGF- $\beta 1$ and PDGF-B led to a marked macrophage influx and an expansion of the connective tissue cell population. Over time, this effect was sustained in mice treated with TGF- $\beta 1$, whereas it was partially reversible in mice treated with PDGF-B. On the basis of structure and expression of phenotypical markers, the emerging connective tissue cell population may originate from microvascular pericytes. TGF- $\beta 1$ induced expansion of connective tissue cells with a myofibroblast phenotype, whereas PDGF-B induced a fibroblast phenotype negative for $\alpha$-smooth muscle actin. TGF- $\beta 1$ and PDGF-B overexpressions mediated distinct effects on mRNA transcript levels of fibrillar procollagens, their modifying enzymes, small leucin-rich repeat proteoglycans, and matricellular proteins affecting both the composition and the quantity of the extracellular matrix. This study offers new insight into the effects of PDGF-B and TGF- $\beta 1$ on the vasculature and connective tissue in vivo. (Am J Pathol 2013, 182: 2132-2146; http://dx.doi.org/10.1016/j.ajpath.2013.01.054)
\end{abstract}

Tissue repair processes and other reactive conditions in adult tissues such as tumor stroma formation and chronic inflammatory conditions share several features, including infiltration of inflammatory cells, activation of blood vessels, and angiogenesis. ${ }^{1-3}$ Furthermore, in these conditions connective tissue cells become activated and play a central role in the synthesis and organization of extracellular matrix components. ${ }^{4}$ Acute injury causes normal mesenchymal cells to convert to a fibrogenic phenotype that, if not appropriately controlled, leads to fibrosis. Thus, tight control of connective tissue cells is crucial for optimal tissue regeneration and repair. ${ }^{4,5}$ Neosynthesis of connective tissue is a process involved not only in the wound healing response that maintains organ structure and integrity after tissue damage but also contributes to a variety of human pathologies. In many pathologies as well as suboptimal tissue repair, persistent activation of connective tissue cells leads to excessive extracellular matrix deposition, dominated by collagen type I, leading in turn to fibrosis and ultimately organ dysfunction. $^{2-5}$ To maintain tissue functionality, not only the amount of extracellular matrix needs to be controlled, but

Supported by grants from the Children's Cancer Foundation of Sweden, The Swedish Cancer Foundation, The Swedish Medical Research Council, Uppsala University, and the Lions Cancer Foundation.

Current address of T.F., Sanford Burnham Medical Research Institute, University of California, Santa Barbara, CA; of T.v.W., School of Biosciences, University of Birmingham, Birmingham, United Kingdom. 
also how it is organized and remodeled. ${ }^{4-6}$ These processes are tightly orchestrated by a number of molecules, including collagen-modifying enzymes, small leucin-rich repeat proteoglycans (SLRPs), and other matricellular proteins. ${ }^{5,7}$ In some instances, tissue damage is reversible with the reinstatement of organ architecture and function. ${ }^{8}$ Mechanisms leading to either reinstatement of organ function or progression toward chronic fibrosis and organ dysfunction display similarities in their initial pathophysiology. However, the underlying mechanisms that determine the eventual outcome are largely unknown.

Here, we focused on two growth factors, namely transforming growth factor (TGF)- $\beta 1$ and platelet-derived growth factor (PDGF)-B, which are known to be of central importance in blood vessel and connective tissue cell function. PDGF-B is important because it is one of the most potent mesenchymal cell mitogens, and TGF- $\beta 1$ is important because it is a potent inducer of extracellular matrix components by mesenchymal cells. ${ }^{9-11}$ When overexpressed, TGF- $\beta 1$ is a well-known inducer of fibrosis in a wide range of pathologies. ${ }^{12}$ Documented effects include driving differentiation of mesenchymal cells such as fibroblasts toward profibrotic myofibroblasts, ${ }^{4}$ but also to induce epithelial-tomesenchymal transition and hence tissue fibrosis. ${ }^{13}$ PDGF-B has also been implicated in fibrosis in a number of diseases that range from liver fibrosis to systemic sclerosis. ${ }^{14,15} \mathrm{An}$ important role for PDGF-B in angiogenesis is recognized through its effects on PDGF $\beta$-receptor-bearing pericytes, which indirectly modulate endothelial cell behavior. ${ }^{16,17}$ TGF- $\beta 1$ has also been shown to be involved in different aspects of angiogenesis, including vessel stabilization through its effects on endothelial cells, pericytes, and basement membrane deposition. ${ }^{18}$

In the present study, we used adenoviral vectors engineered to express PDGF-B or a constitutively active form of TGF- $\beta 1$ and injected them into normal mouse skin to investigate the effect of transient overexpression of these factors in a normal tissue in vivo. Tissues were investigated on the structural as well as the molecular level with special emphasis on the vasculature and connective tissue components of the skin.

\section{Materials and Methods}

\section{Animals and Adenoviral Vectors}

Athymic mice of the strain CByJ.Cg-Foxn $1^{\mathrm{nu}} / \mathrm{J}$ were purchased from The Jackson Laboratory (Bar Harbor, MA) at an age between 8 and 12 weeks. Mice were injected with adenoviruses diluted in sterile PBS. Animals were anesthetized with Avertin (Sigma-Aldrich, Stockholm, Sweden) at a dosage of $240 \mathrm{mg} / \mathrm{kg}$. They were housed in a pathogenfree environment at the animal facility in the Biomedical Center at Uppsala University. They were fed water and food pellets ad libitum. The Uppsala Ethical Committee for Animal Research approved all animal experiments.
Adenoviral vectors were used to overexpress TGF- $\beta 1$ (Ad-TGF- $\beta 1$ ), PDGF-B (Ad-PDGF-B), and green fluorescent protein (Ad-GFP), with the last vector serving as control virus. Vectors were injected into mouse ears in nude mice to investigate the effects of transient overexpression of these growth factors in normal skin. Ears were harvested after 3, 7, and 14 days, and effects in the tissues on both the structural and molecular level were analyzed. Viral titers of $2.8 \times 10^{8}$ ifu $/ \mathrm{mL}$ for Ad-TGF- $\beta 1,4.2 \times 10^{8}$ ifu $/ \mathrm{mL}$ for AdPDGF-B, and $3.0 \times 10^{8}$ ifu/mL for Ad-GFP were injected into the skin of the ear in a total volume of $30 \mu \mathrm{L}$. The AdPDGF-B vector encoding the murine PDGF-B cDNA $^{19}$ was a kind gift from Prof. Seppo Ylä-Herttuala (University of Koupio, Finland). This construct results in the synthesis of biologically active PDGF-B. ${ }^{19}$ The Ad-GFP that encoded the GFP cDNA was purchased from Qbiogene (Montreal, Quebec, Canada). The Ad-TGF- $\beta 1$ vector that encoded the TGF- $\beta 1$ cDNA was generated with the AdEasy system (Qbiogene). Briefly, the pRK5 ${ }_{1} \mathrm{C}_{2} \mathrm{~S}_{2}$ plasmid that contained the TGF- $\beta 1$ cDNA was used for further generation of recombinant adenoviruses. This cDNA was modified so that the two cysteine codons at positions 223 and 225 were replaced by serine codons TCT and AGC. The wild-type gene secretes a latent full-length form of TGF- $\beta 1$ that first needs to be proteolytically cleaved to generate the bioactive form of the TGF- $\beta 1$ protein. The site-directed mutagenesis mentioned above results directly in a high expression of bioactive TGF- $\beta 1 .^{20}$ To obtain the TGF- $\beta 1$ cDNA the pRK5 ${ }_{1} \mathrm{C}_{2} \mathrm{~S}_{2}$ plasmid was digested with EcoRI and HindIII and blunted with Klenow Large Fragment of Polymerase I (MBI Fermentas, Amherst, NY). A pShuttle vector was subsequently digested with $\mathrm{XbaI}$ and blunted, followed by ligation of the cDNA with the pShuttle vector. The pShuttle vector was sequenced to confirm the correct orientation of the cDNA insert. Preparation of high-titer virus stocks and up-scaling of viral particles was performed by infecting HEK293 cells. Purification of viral particles was done with the AdenoX virus purification kit (Clontech, Mountain View, CA), and virus titers were measured with the Adeno$\mathrm{X}$ rapid titer kit (Clontech). To confirm biological activity of TGF- $\beta 1$ mink lung epithelial cells were used that had been stably transfected with the luciferase reporter gene under the control of the TGF- $\beta 1$ inducible promoter plasminogen activator inhibitor $1 .^{21}$ Conditioned medium from COS-7 cells infected with different amounts of Ad-TGF- $\beta 1$ was subsequently added to confluent mink lung epithelial cells, and after 48 hours an increase in luciferase activity was observed, indicating that the construct coded for biologically active TGF- $\beta 1$ protein (data not shown).

\section{Tissue Harvesting}

Adenovirus-transduced ears were excised, put on ice, trimmed with a scalpel, immediately snap-frozen in liquid propane, and then transferred to liquid nitrogen, pending cryosectioning. Adenovirus-transduced ears to be prepared 
for plastic-embedded sections $(1 \mu \mathrm{m})$ were excised and put in $2.5 \%$ buffered glutaraldehyde and subsequently subjected to treatment with Osmium tetroxide, propylene oxide, and finally embedded in plastic overnight. Plastic-embedded tissues were stained with Giemsa ${ }^{22}$ or a $1 \%$ toluidine solution diluted in $2 \%$ borax.

\section{Antibodies and Immunostainings}

The following primary antibodies were used for immunohistochemical staining: the fluorescein isothiocyante-labeled monoclonal antibody (mAb) against smooth muscle $\alpha$-actin ( $\alpha$-SMA), clone 1A4 (Sigma-Aldrich) recognizing $\alpha$-SMA in smooth muscle cells, myofibroblasts, and pericytes ${ }^{23}$; the biotinylated mAb anti-mouse CD31 (Pharmingen, San Diego, CA) detecting platelet endothelial cell adhesion molecule (PECAM)-1 expressed on endothelial cells; the mAb anti-reticular fibroblast marker (RFM), clone ER-TR7 recognizing fibroblasts ${ }^{24}$ (Cedarlane Laboratories, Burlington, Ontario, Canada); the $\mathrm{mAb}$ anti-collagen type IV used as a marker for basement membrane; the $\mathrm{mAb}$ anti-desmin, a cytoskeletal component; the polyclonal antibody against procollagen type I used as a marker for neosynthesis of collagen type I (Abcam, Cambridge, UK); the $\mathrm{mAb}$ anti-NG2 recognizing the mouse equivalent to the human high molecular weight-melanoma associated antigen used as a marker for pericytes ${ }^{22,25}$ (Chemicon, Temacula, CA); the polyclonal antibody anti-fibromodulin ${ }^{26}$ a gift from Dr. Åke Oldberg (Lund University, Sweden); and the mAb F4/80 recognizing macrophages (Serotec, Raleigh, NC).

For detection of primary antibodies in immunofluorescence staining, the following secondary antibodies and avidin conjugates were used: Texas Red-conjugated goat anti-rat IgG; Texas Red-conjugated goat anti-rabbit IgG and biotinylated goat anti-rabbit IgG (Vector Laboratories, Burlingame, CA); streptavidin Alexa Fluor 350 (Molecular Probes, Eugene, OR); and avidin-conjugated fluorescein isothiocyante and Texas Red (Vector Laboratories). Normal rabbit and goat serum was from Serotec. Triple immunofluorescence staining was performed as previously described. ${ }^{22}$

Immunohistochemical detection of PECAM-1, RFM, and $\mathrm{F} 4 / 80$ expression was performed on $6-\mu \mathrm{m}$-thick frozen sections. The secondary antibody biotinylated rabbit anti-rat IgG (Vector Laboratories) was then added, followed by detection with the Vectastain ABC Elite kit (Vector Laboratories) and developed with the DAB Plus substrate kit (Zymed Laboratories, Carlsbad, CA). Sections were counterstained with hematoxylin (SigmaAldrich). All antibodies were diluted in a solution containing PBS pH 7.4, supplemented with $0.1 \%$ bovine serum albumin, $150 \mathrm{mmol} / \mathrm{L}$ tranexamic acid, $20 \mu \mathrm{g} / \mathrm{mL}$ aprotinin (3 to $7 \mathrm{TIU} / \mathrm{mg}$ ), $1.8 \mathrm{mmol} / \mathrm{L}$ EDTA, $2 \mathrm{mmol} / \mathrm{L}$ iodoacetic acid, and $0.2 \%$ Tween-80 (Sigma-Aldrich). ${ }^{16}$

\section{Vascular Density Quantification}

Quantification of vascular density from Ad-PDGF-B $(n=3)$, Ad-TGF- $\beta 1(n=3)$, and Ad-GFP $(n=4)$ was performed on images of $25-\mu \mathrm{m}$ thick sections stained with PECAM-1 and quantified with the software ImageJ version $1.46(\mathrm{NIH}$, Bethesda, MD). The area of the dermis in the reactive site and corresponding dermis of controls were measured, and the number of PECAM-1-positive structures was counted manually. Statistical analysis was performed with Student $t$-test, and $P<0.05$ was considered statistically significant.

\section{RNA Extraction and Real-Time Quantitative PCR}

For these experiments, the injection site where the adenoviral vectors were introduced was marked with ink. Ears were excised and trimmed to remove portions of the ear that were not in the vicinity of the injection site to maximize the proportion of RNA derived from the active site. The remaining tissues were then immediately frozen in liquid nitrogen, pending further analysis. Total RNA from Ad-GFP $(n=5)$, Ad-PDGF-B $(n=5)$, and Ad-TGF- $\beta 1(n=5)$ transduced ears at day 7 was extracted with RNeasy Mini Kit (Qiagen, Sollentuna, Sweden) according to the manufacturer's instructions. Total RNA was treated with DNase I (Qiagen) for 20 minutes at room temperature to remove genomic DNA. RNA integrity was verified with electrophoresis on a $2 \%$ agarose gel. Total RNA $(1 \mu \mathrm{g})$ was subjected to first-strand cDNA synthesis with Superscript III First-Strand Synthesis Supermix for real-time quantitative PCR (Invitrogen, Stockholm, Sweden) containing a mix of oligo(dT) $)_{20}$ and random hexamer primers. The cDNA was treated with $2 \mathrm{U}$ of $\mathrm{RNase} \mathrm{H}\left(37^{\circ} \mathrm{C}\right.$ for 20 minutes $)$ to remove carry-over contamination of RNA. Real-time quantitative PCR for each sample was performed on LightCycler (Roche Applied Science, Mannheim, Germany) in duplicates or triplicates by mixing cDNA with Maxima SYBR Green realtime quantitative PCR Master Mix (Fermentas, St. Leon-Rot, Germany) and gene-specific primer pairs (Table 1). Amplification results were analyzed with LightCycler software version 3 (Roche Applied Science). Threshold cycle values for each gene were calculated and normalized to the threshold cycle value of the internal standard glyceraldehyde3-phosphate dehydrogenase. Next, relative gene expression was compared between the treatment groups. The data are presented as fold change over the Ad-GFP control. Statistical analysis was performed with a one-way analysis of variance with Bonferroni posttest. $P<0.05$ was considered statistically significant.

\section{Results}

Hypercellularity and Increase in Tissue Volume in Ad-PDGF-B and Ad-TGF- $\beta 1$

Both PDGF-B and TGF- $\beta 1$ overexpression induced a temporally defined and characteristic sequence of events in the dermal and muscular layer of mouse skin. Ad-GFPtreated skin evoked no response compared with nontreated skin (data not shown). Ad-GFP tissues were subsequently 
Table 1 List of Primers

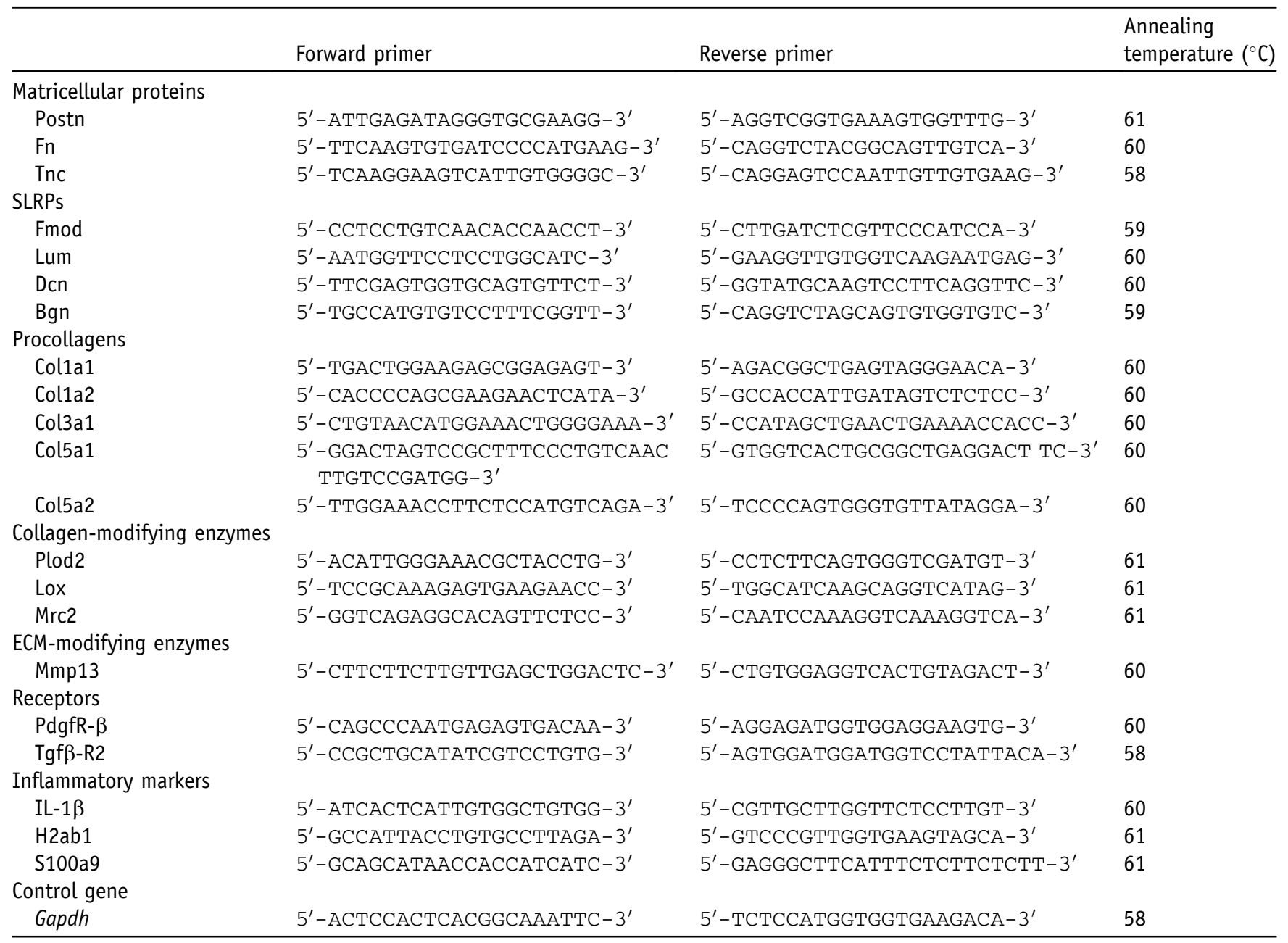

Gapdh, glyceraldehyde-3-phosphate dehydrogenase.

used as negative controls throughout this study. Hypercellularity and an increase in dermal thickness compared with Ad-GFP were already noted on day 3, were marked on day 7 , and persisted on day 14 in both Ad-PDGF-B and Ad-TGF$\beta 1$ (Figure 1, A-H).

\section{Effects of Ad-PDGF-B and Ad-TGF- $\beta 1$ on the Vasculature}

A concomitant increase in vessel density was not observed in either Ad-PDGF-B or Ad-TGF- $\beta 1$ (Figure 1, A-H). Rather, in the dermis in both treatment groups, the density of PECAM-1 ${ }^{\text {pos }}$ structures was significantly decreased already on day 3 and remained so during the entire treatment period in both conditions compared with Ad-GFP $(P<0.05)$ (Figure 2). No significant differences in vascular density were detected in Ad-PDGF-B compared with Ad-TGF- $\beta 1$ at any time point. In 3 days Ad-PDGF-B but not in Ad-TGF$\beta 1$ small accumulations of endothelial cells that represented early glomeruloid bodies were observed in the endothelial lining of mother vessels (Figure 3, A and B), that is, enlarged, activated, hyperpermeable, thin-walled, pericytepoor precursor vessels that ultimately form new blood vessels. $^{22,27}$ These glomeruloid bodies increased in mass (Figure 3, C, D, and F) to the point where mature glomeruloid bodies entirely obliterated the vascular lumen (Figure 3E). In close apposition to early glomeruloid bodies at day 3, clusters of RFM ${ }^{\text {pos }}$ cells were observed (Figure $3 G$ ). The glomeruloid bodies did not persist in that they were undetectable at day 14 (data not shown). Interspersed within areas of marked hypercellularity, small clusters of PECAM$1^{\text {pos }}$ cells could be identified that displayed no apparent vessel structure in both Ad-PDGF-B and Ad-TGF- $\beta 1$ (Figure $3 \mathrm{H}$ ) (data not shown). Triple immunofluorescence staining was performed on sections with antibodies against PECAM-1, $\alpha$-SMA, and NG2, or collagen type IV. Accumulations of $\alpha$-SMA ${ }^{\text {pos }}$ cells were observed that were not apparently associated with PECAM-1 ${ }^{\text {pos }}$ endothelium (Figure 3, I-L). At higher magnification $\alpha-\mathrm{SMA}^{\text {pos }}$ vessellike structures were observed that did not contain a lining of PECAM-1 ${ }^{\text {pos }}$ endothelial cells (Figure 3, M-P). Furthermore, $\alpha$-SMA ${ }^{\text {pos }}$ vessel-like structures were observed that 
Ad-GFP

A

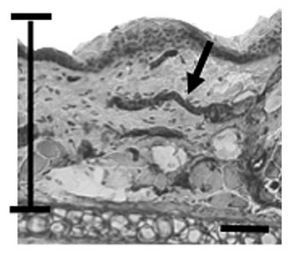

Ad-GFP

E

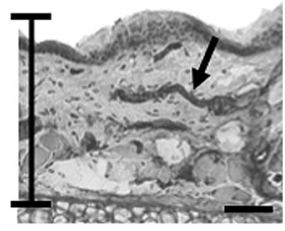

Ad-PDGF-B

B

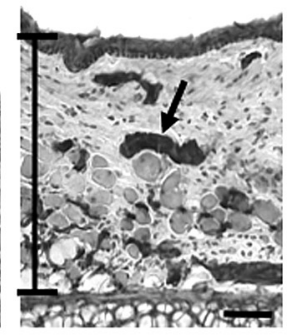

Ad-TGF- $\beta 1$

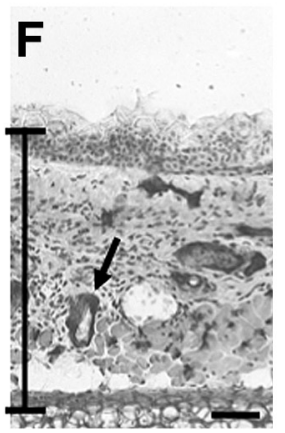

Ad-PDGF-B

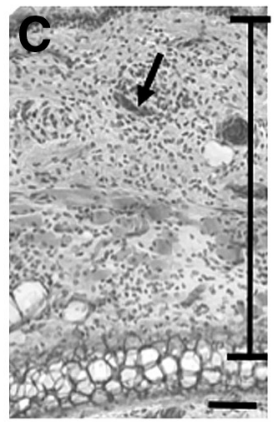

Ad-TGF- $\beta 1$

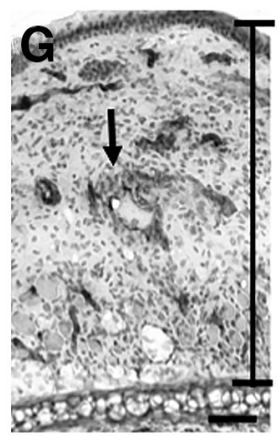

Ad-PDGF-B

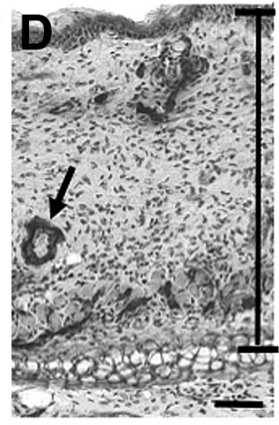

Ad-TGF- $\beta 1$

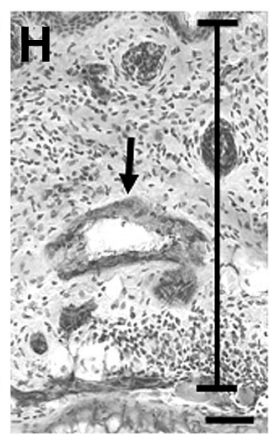

Figure 1 Increases in tissue thickness and cellularity in Ad-PDGF-B and Ad-TGF- $\beta 1$ compared with Ad-GFP. Immuno-enzyme labeling with PECAM-1 of sections from mouse skin injected with Ad-GFP (A and E; identical frames for comparison), Ad-PDGF-B, or TGF- $\beta 1$ harvested at 3 (B and F), 7 (A, C, E, and $\mathbf{G})$, and 14 (D and $\mathbf{H})$ days after injection. Arrows indicate PECAM- $1^{\text {pos }}$ vessels $(\mathbf{A}-\mathbf{H})$. Scale bars: $100 \mu \mathrm{m}(\mathbf{A}-\mathbf{H})$. expressed the basement membrane component collagen type IV but were PECAM-1 ${ }^{\text {neg }}$ (Figure 3, Q-T).

\section{Microvascular Pericytes and Emerging Connective Tissue Cells in Ad-PDGF-B and Ad-TGF- $\beta 1$}

In Ad-GFP (Figure 4A) and normal skin (data not shown), pericytes were closely juxtaposed to the endothelial lining in agreement with the definition of a pericyte. In 3-day Ad-PDGF-B (Figure 4, B and C) and Ad-TGF- $\beta 1$ (data not shown), activation of both pericytes and endothelial cells was noted, that is, enlarged protruding nuclei. At this time point pericytes were detached from the vascular wall of blood vessels, and small accumulations of perivascular connective tissue cells was apparent in Ad-PDGF-B (Figure 4C) and Ad-TGF- $\beta 1$ (Figure 4D). Concomitantly, an influx of inflammatory cells was observed already on day 3 (Figure 4, E and F). In 7 day Ad-PDGF-B and Ad-TGF- $\beta 1$ in proximity to mother vessels, circumferential accumulations of perivascular connective tissue cells, had emerged (Figure 4, $\mathrm{G}$ and $\mathrm{H})$.

\section{Characterization of Cell Types in Ad-PDGF-B and Ad-TGF- $\beta 1$}

PECAM-1 ${ }^{\text {pos }}$ endothelial cells could not account for the marked hypercellularity in the dermis and the muscular layer observed in Ad-PDGF-B and Ad-TGF- $\beta 1$. F4/80, a marker for macrophages (Figure 5, A-J) and RFM that detected pericytes and fibroblasts (Figure 6, A-I) were used to investigate if these cell types might be responsible for the observed hypercellularity. Macrophages were sparse in both dermis and the muscular layer in Ad-GFP (Figure 5, A and B). Macrophage infiltration into the dermis (Figure 5, $\mathrm{C}$ and D) as well as the muscular layer (Figure 5, E and F) was apparent already after 3 days (data not shown) and marked after 7 days (Figure 5, C-F) in both Ad-PDGF-B and Ad-TGF- $\beta 1$. On day 14 , macrophage infiltration persisted in the dermis in Ad-PDGF-B and Ad-TGF- $\beta 1$ (Figure 5, G and $\mathrm{H}$ ). However, at this time point the $\mathrm{F} 4 / 80^{\text {pos }}$

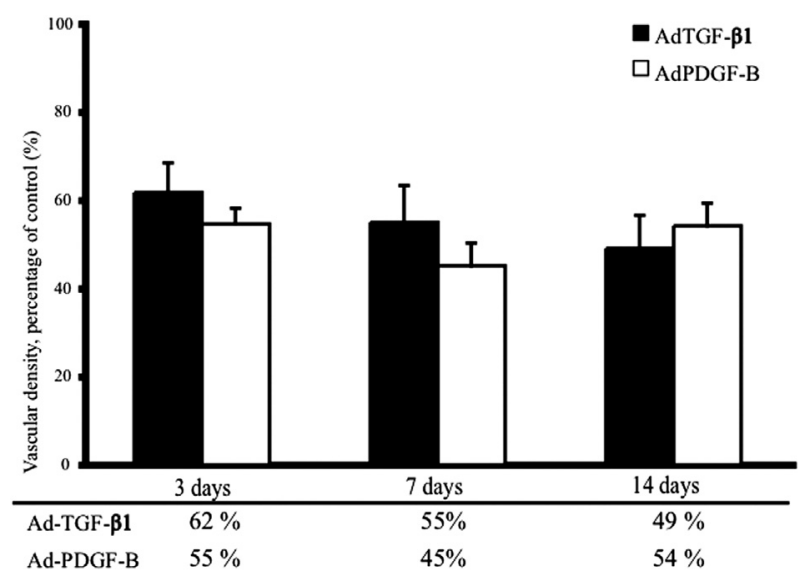

Figure 2 Decrease in vascular density in Ad-PDGF-B and Ad-TGF- $\beta 1$. Vessel density in the dermis was calculated within the reactive site. Number of PECAM $-1^{\text {pos }}$ structures per millimeter squared was manually counted. Data are presented as percentages of the number of blood vessels compared with control Ad-GFP. $P<0.05$ with Student's $t$-test was considered significant. 

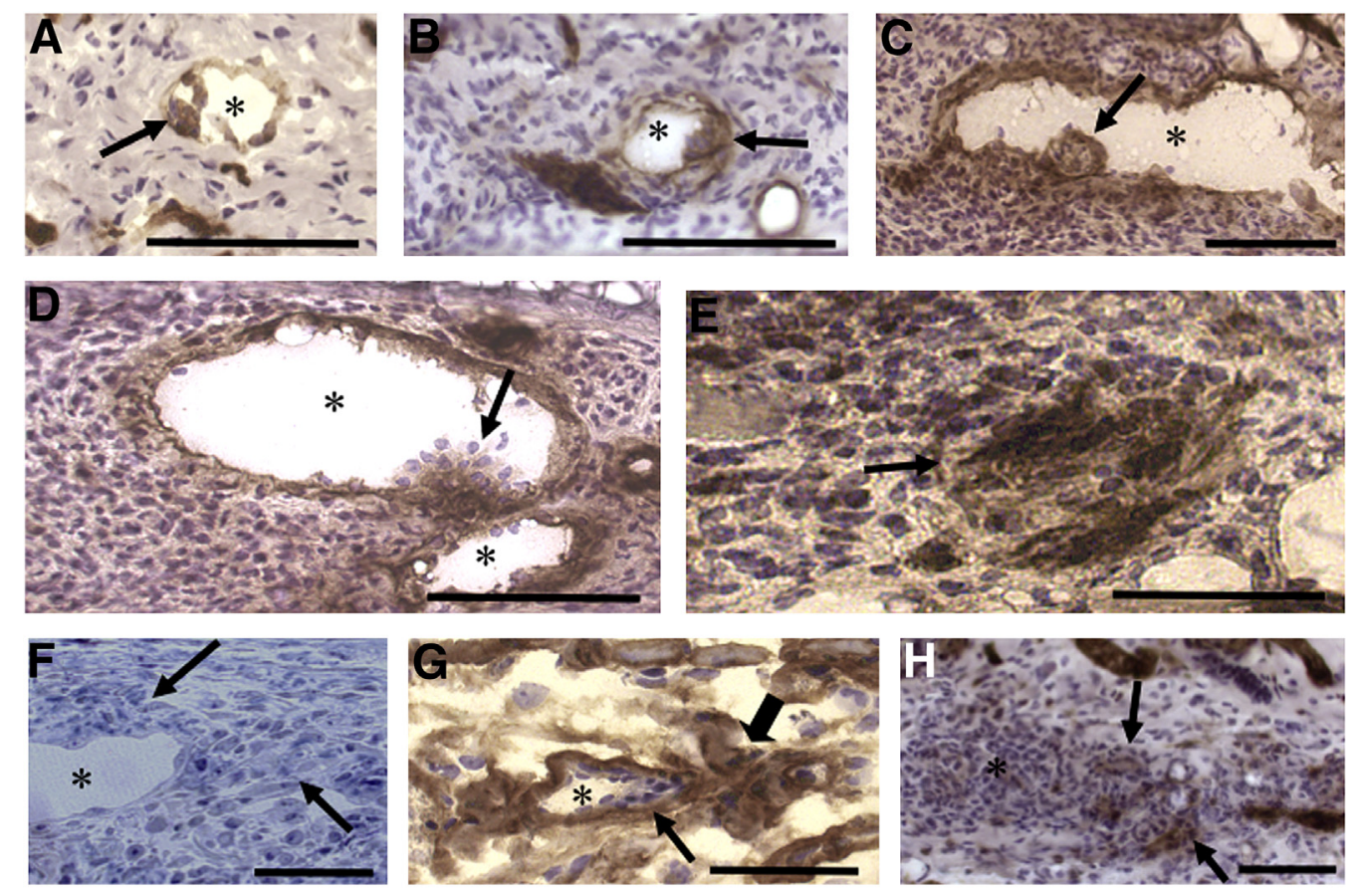

\section{$\operatorname{cd} 31 / \alpha-S M A / N G 2$}
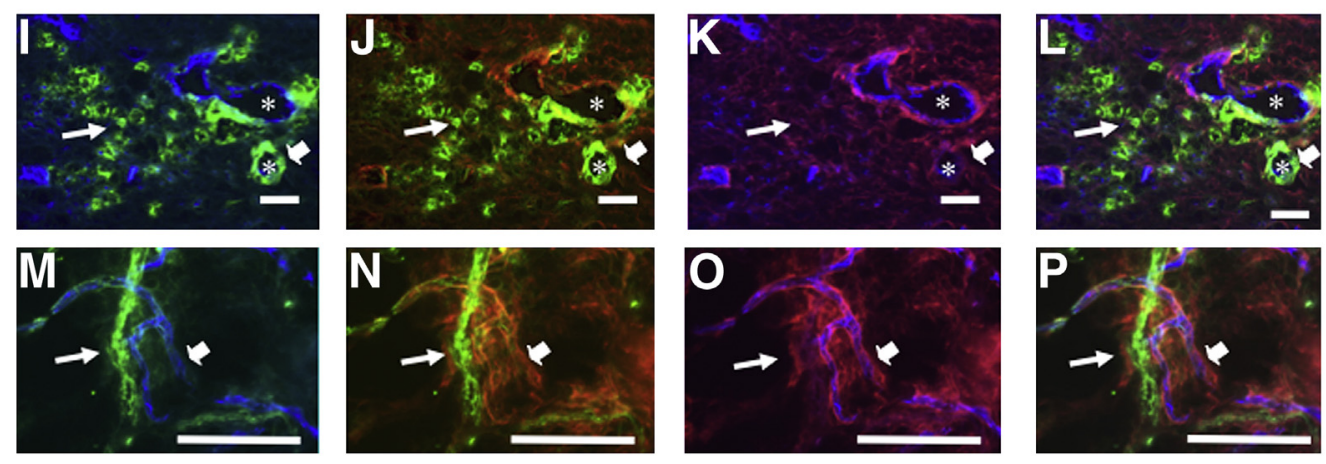

cd31/a-SMA/Collagen IV
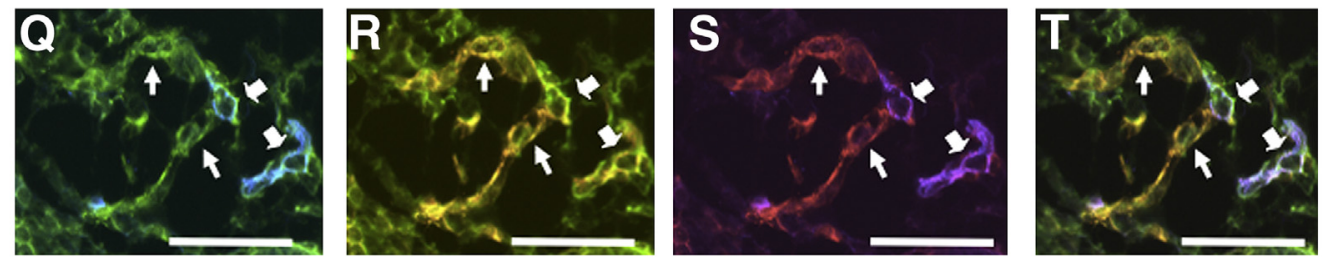

Figure 3 Formation of glomeruloid bodies and vascular obliteration in Ad-PDGF-B. Immuno-enzyme labeling with the mAb PECAM-1 (A-E and $\mathbf{H})$ or mAb RFM (G) or triple immunofluorescence staining (I-T) on sections harvested at $3(\mathbf{A}$ and $\mathbf{B})$ and 7 (C-T) days after injection. $\mathbf{A}$ and $\mathbf{B}$ : Accumulations of endothelial cells forming early glomeruloid bodies (arrow) in blood vessel (asterisk). C and D: Increase in size of glomeruloid bodies (arrow) in blood vessel (asterisk). E: Accumulations of PECAM- $1^{\text {pos }}$ cells (arrow) with no discernable lumen forming mature glomeruloid bodies. F: Accumulations of cells (arrows) in the wall of a blood vessel (asterisk) in 1- $\mu \mathrm{m}$ Giemsa-stained Epon section. G: A cluster of RFM ${ }^{\text {pos }}$ cells (block arrow) in close proximity to an early glomeruloid body (arrow) in a blood vessel (asterisk). H: Weakly PECAM-1 ${ }^{\text {pos }}$ endothelial cells with no apparent vessel structure (arrows) amid areas of hypercellularity (asterisk). I-L: PECAM- $1^{\text {neg }} / \alpha-S M A^{\text {pos }} / N G 2^{\text {pos }}$ cell clusters (arrow) in contrast to PECAM- $1^{\text {pos }} / \alpha-S M A^{\text {pos }} / N G 2^{\text {pos }}$ blood vessels (block arrow). M-P: PECAM- $1^{\text {neg }} / \alpha-S M A^{\text {pos }} / N G 2^{\text {pos }}$ vessel-like structure (arrow) in contrast to a PECAM- $1^{\text {pos }} / \alpha-S M A^{\text {neg }} /$ NG $2^{\text {pos }}$ blood vessel (block arrow). $\mathbf{Q}-\mathrm{T}$ : PECAM- $1^{\text {neg }} / \alpha-$ SMA ${ }^{\text {pos }} /$ collagen IV ${ }^{\text {pos }}$ vessel-like structures (arrows) in contrast to PECAM- $1^{\text {pos }} / \alpha-S M A^{\text {pos }} /$ collagen IV ${ }^{\text {pos }}$ blood vessels (block arrows). Scale bars: $50 \mu \mathrm{m}(\mathbf{A}-\mathrm{T})$.

macrophage population was markedly diminished in the muscular layer of Ad-PDGF-B (Figure 5I). In contrast, macrophage infiltration in Ad-TGF- $\beta 1$ persisted in the muscular layer (Figure 5J).
The reticular fibroblast marker has previously been described as specific for fibroblasts. ${ }^{24}$ However, we have recently found that RFM is also expressed in vascular structures and more specifically in microvascular pericytes ${ }^{28}$ 

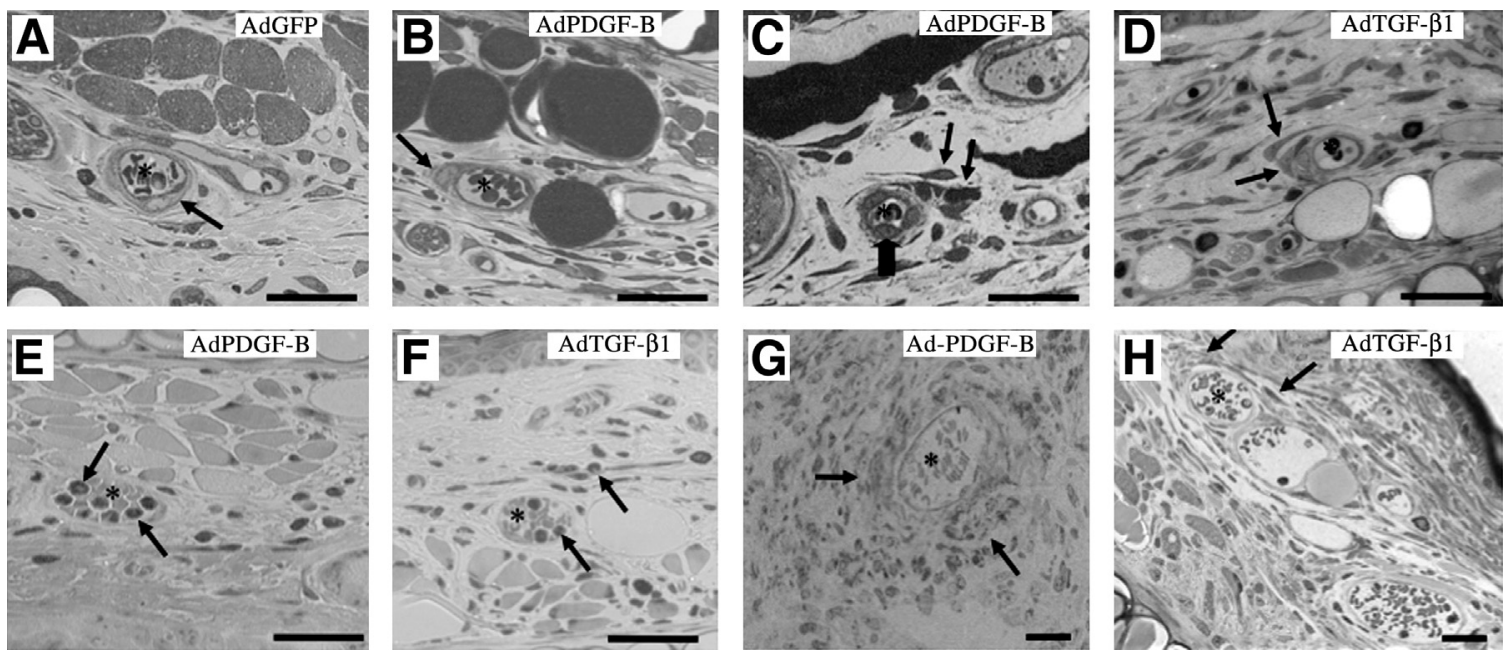

Figure 4 Activation of pericytes, infiltration of inflammatory cells, and subsequent perivascular expansion of connective tissue cells in Ad-PDGF-B and AdTGF- $\beta 1$. Giemsa-stained Epon sections $(1 \mu \mathrm{m})$ from mouse skin injected with Ad-GFP, Ad-PDGF-B, or Ad-TGF- $\beta 1$ were harvested at $3(\mathbf{A}-\mathbf{F})$ or 7 (G and $\mathbf{H})$ days after injection. A: A pericyte (arrow) juxtaposed to the endothelial lining in a blood vessel (asterisk) in Ad-GFP. B: An activated pericyte with a large nucleus (arrow) in a blood vessel (asterisk) in 3-day Ad-PDGF-B. C and D: Activated endothelial cells with large nuclei (block arrow) in a blood vessel (asterisk) with a small accumulation of connective tissue-like cells (arrows) in the immediate perivascular space in 3-day Ad-PDGF-B (C) and Ad-TGF- $\beta 1$ (D). E and F: Accumulation of inflammatory cells (arrows) in and around a mother vessel (asterisk) in 3-day Ad-PDGF-B (E) and Ad-TGF- $\beta 1$ (F). $\mathbf{G}$ and $\mathbf{H}$ : Accumulation of cells (arrows) in the perivascular space surrounding a mother vessel (asterisk) in 7-day Ad-PDGF-B (G) and Ad-TGF- $\beta 1$ (H). Scale bars: $50 \mu \mathrm{m}(\mathbf{A}-\mathbf{H})$.

as well as interstitial connective tissue cells exemplified here in 7-day Ad-GFP (Figure 6A). Expansion of the RFM ${ }^{\text {pos }}$ cell population was apparent already after 3 days in the dermis and to a lesser extent in the muscular layer in both conditions (data not shown). This increase in connective tissue cells was marked at day 7 and constituted the main mass of cells in the dermis in both Ad-PDGF-B and Ad-TGF- $\beta 1$ (Figure 6, B and C). Expansion of connective tissue cells in the muscular layer was also prominent at this time point in both conditions (Figure 6, D and E). On day $14 \mathrm{RFM}^{\text {pos }}$ connective tissue cells remained the dominating cell type in the dermis of both Ad-PDGF-B and Ad-TGF- $\beta 1$ (Figure 6, F and $\mathrm{G}$ ). However, at this time point, the connective tissue cell population was markedly diminished in the muscular layer of Ad-PDGF-B (Figure 6H), whereas the elevated connective tissue cell population persisted in the muscular layer of Ad-TGF- $\beta 1$ (Figure 6I).

\section{Phenotypical Characterization of Connective Tissue Cells in Ad-PDGF-B and Ad-TGF- $\beta 1$}

To analyze the phenotype of the emerging connective tissue cells in more detail, sections from day-7 Ad-PDGF-B and Ad-TGF- $\beta 1$ were subjected to triple immunofluorescence labeling. Antibodies that recognize PECAM-1 in conjunction with antibodies against $\alpha$-SMA, NG2, RFM, and procollagen type I were used (Figure 7). In Ad-GFP, $\alpha$-SMA and, to a lesser extent, NG2 were expressed in PECAM-1 ${ }^{\text {pos }}$ vascular structures. No detectable NG2 or $\alpha$-SMA expression was discerned outside of the vasculature (Figure 7A). In Ad-GFP RFM was expressed in both $\alpha-\mathrm{SMA}^{\text {pos }}$ (Figure 7B) and $\mathrm{NG}^{\text {pos }}$ (Figure 7C) pericytes as well as in nonvascular interstitial connective tissue cells that were $\alpha-\mathrm{SMA}^{\text {neg }} / \mathrm{NG} 2^{\text {neg }}$ (Figure 7 ,
$B$ and $C)$. In vascular structures, $\alpha$-SMA expression decreased, whereas NG2 expression increased in Ad-PDGF-B. Furthermore, accumulations of cells in the perivascular space surrounding PECAM- $1^{\text {pos }}$ vessels were $\alpha-\mathrm{SMA}^{\text {neg }} / \mathrm{NG}^{\text {pos }}$ (Figure 7D). In Ad-PDGF-B $\alpha-\mathrm{SMA}^{\mathrm{pos}} / \mathrm{RFM}^{\mathrm{pos}}$ cells were identified in vascular structures, whereas cells in the nonvascular compartment were $\alpha-\mathrm{SMA}^{\mathrm{neg}} / \mathrm{RFM}^{\text {pos }}$ (Figure $7 \mathrm{E}$ ). These cells in the nonvascular compartment were $\mathrm{NG}_{2}{ }^{\mathrm{pos}}$ / RFM $^{\text {pos }}$ (Figure 7F). In Ad-TGF- $\beta 1$, accumulations of perivascular cells were $\alpha$-SMA ${ }^{\text {pos }}$ and to a lesser extent $\mathrm{NG}^{2 \text { pos }}$ (Figure 7G). In Ad-TGF- $\beta 1 \alpha-$ SMA $^{\text {pos }} /$ RFM $^{\text {pos }}$ cells were identified in the vasculature as well as in accumulations of cells in the perivascular space (Figure $7 \mathrm{H})$ that were $\mathrm{NG}^{\text {neg }}$ (Figure 7I). In Ad-PDGF-B expression of procollagen type I, a marker for collagen type I neosynthesis was concentrated to the perivascular space and colocalized with $\mathrm{NG} 2^{\text {pos }}$ cells (Figure 7, J-M). In Ad-TGF- $\beta 1$, procollagen type I expression colocalized with $\alpha$-SMA ${ }^{\text {pos }}$ cells (Figure 7, N-Q). Desmin was expressed in a subpopulation of pericytes associated with the microvasculature but was not expressed in interstitial cells (data not shown).

\section{Partial Regression of Connective Tissue Cell Populations over Time in Ad-PDGF-B But Not Ad-TGF- $\beta 1$}

To temporally define the emergence of the connective tissue cell phenotypes in Ad-PDGF-B and Ad-TGF- $\beta 1$ sections from day 3 , day 7 , and day 14 was subjected to triple immunofluorescence labeling. Antibodies that recognize PECAM-1 in conjunction with antibodies against $\alpha$-SMA and NG2 were used (Figure 8). Pericytes in Ad-GFP expressed $\alpha$-SMA and to a low extent NG2 in PECAM-1 ${ }^{\text {pos }}$ vessels in the dermis (Figure 8A) and in the muscular layer 

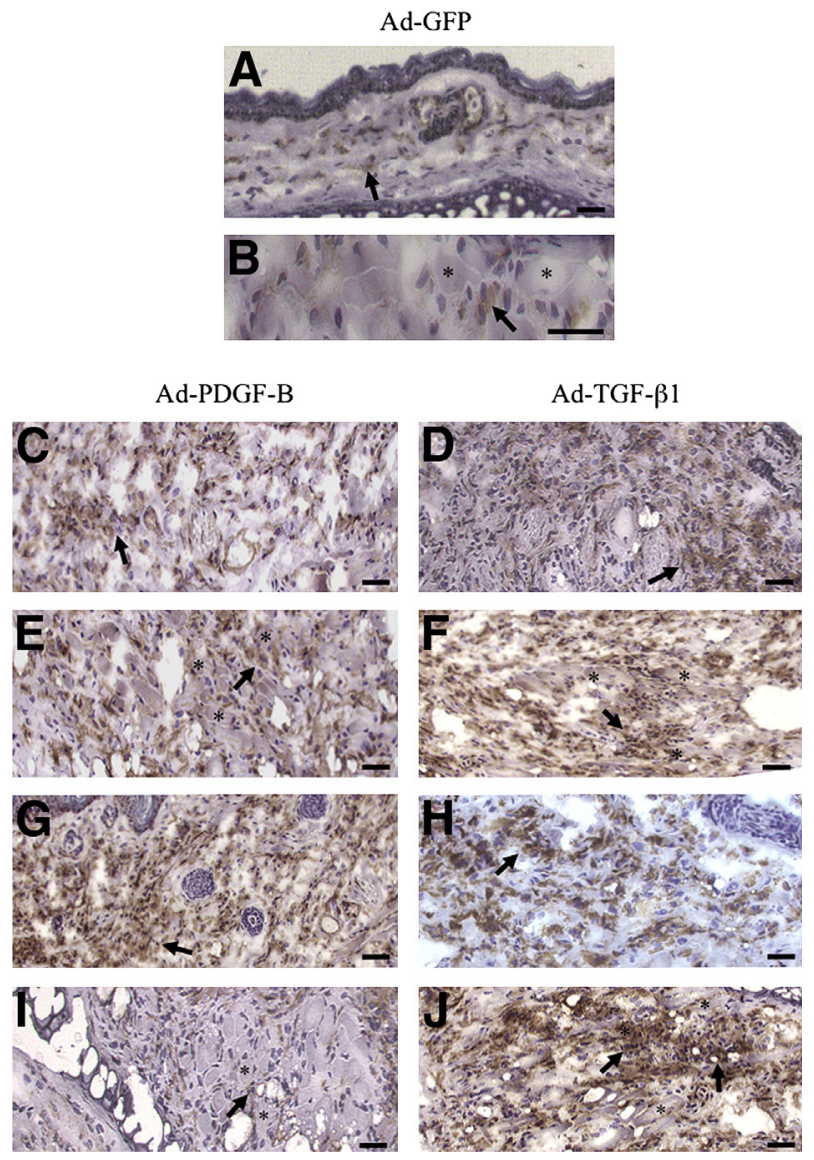

Figure 5 Increase in macrophage infiltration in Ad-PDGF-B and Ad-TGF$\beta 1$. Immuno-enzyme labeling of macrophages with the mAb F4/80 in $\mathrm{Ad}$ GFP, Ad-PDGF-B, or Ad-TGF- $\beta 1$ was harvested at $7(\mathbf{A}-\mathbf{F})$ and $14(\mathbf{G}-\mathbf{J})$ days after injection. Asterisks indicate muscle fibers. (A and $\mathbf{B}$ : Presence of macrophages (arrow) in the dermis (A) and in the muscular layer (B) in AdGFP. C-F: Infiltration of macrophages (arrow) in the dermis (C and $\mathbf{D}$ ) and in the muscular layer ( $\mathbf{E}$ and $\mathbf{F}$ ) at $\mathbf{7}$ days. $\mathbf{G}$ and $\mathbf{H}$ : Macrophage infiltration (arrow) in the dermis at 14 days. I and J: Macrophage infiltration (arrow) in the muscular layer in 14-day Ad-PDGF-B (I) in contrast to persistent macrophage infiltration (arrows) in 14-day Ad-TGF- $\beta 1$ (J). Scale bars: 100 $\mu \mathrm{m}$ (A and $\mathbf{B}) ; 50 \mu \mathrm{m}(\mathbf{C}-\mathbf{J})$.

(Figure 8B). In the muscular layer at 3 days in Ad-PDGF-B, $\alpha$-SMA expression was diminished in microvascular structures that began to express NG2 (Figure 8C). Microvessels in the muscular layer at 3 days in Ad-TGF- $\beta 1$ were $\alpha$-SMA ${ }^{\text {pos }}$ and to a lesser degree NG2 ${ }^{\text {pos }}$ (Figure 8D). At 7 days, in both conditions accumulations of cells were observed interspersed among the muscle fibers, thereby displacing them laterally (Figure 8, E and F). In Ad-PDGF-B these cells were $\alpha-\mathrm{SMA}^{\mathrm{neg}} / \mathrm{NG}^{\mathrm{pos}}$ (Figure $8 \mathrm{E}$ ) in contrast to the corresponding cells in Ad-TGF- $\beta 1$ that were $\alpha-\mathrm{SMA}^{\text {pos }} / \mathrm{NG} 2^{\text {neg }}$ (Figure 8F). At 14 days in Ad-PDGF-B, the accumulations of connective tissue cells observed at 7 days had regressed. Remaining $\alpha-\mathrm{SMA}^{\text {neg }} / \mathrm{NG}^{\text {pos }}$ cells were vessel-associated pericytes (Figure $8 \mathrm{G}$ ). In contrast, the accumulations of $\alpha-\mathrm{SMA}^{\mathrm{pos}} / \mathrm{NG} 2^{\text {neg }}$ cells persisted in the muscular layer in Ad-TGF- $\beta 1$ (Figure 8H). In Ad-PDGF-B (Figure 8I) and Ad-TGF- $\beta 1$ (Figure $8 \mathrm{~J}$ ) the phenotypical marker profile of the connective tissue cell population was similar at 3, 7 (data not shown), and 14 (Figure 8, I and J) days in the dermis compared with the muscular layer (Figure 8, C-H).

\section{mRNA Expression Profiles Coding for Extracellular Matrix Components and Their Modifiers in Ad-TGF- $\beta 1$ and Ad-PDGF-B}

The results show that phenotypically different types of connective tissue cells emerge in Ad-TGF- $\beta 1$ compared with Ad-PDGF-B. To further characterize these two different phenotypes, mRNA expression levels of various extracellular matrix (ECM) components and their modifiers were investigated at the 7-day time point in different treatment groups (Figure 9, A and B). A significant increase in mRNA expression for procollagen type I (Col1a1, Col1a2),
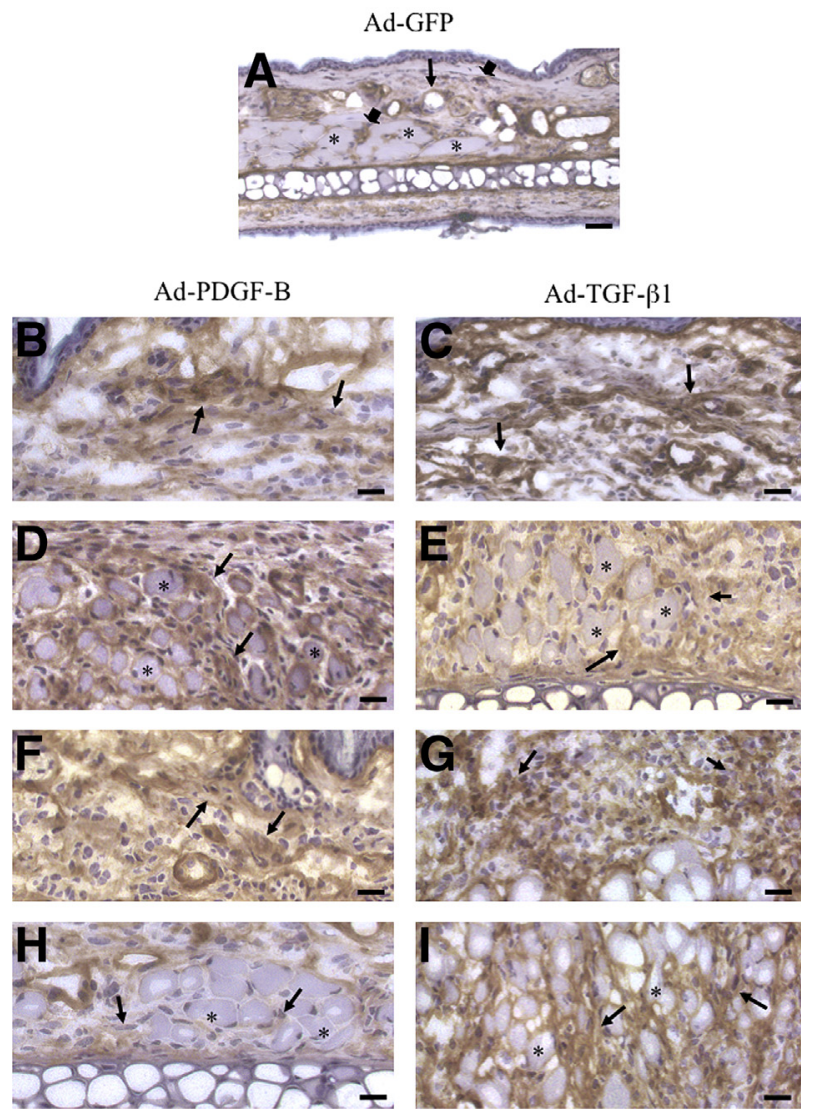

Figure 6 Expansion of the connective tissue cell population in the dermis and the subcutaneous muscular layer in Ad-PDGF-B and Ad-TGF- $\beta 1$. Immunoenzyme labeling of pericytes and fibroblasts with the mAb RFM in Ad-GFP, Ad-PDGF-B, or Ad-TGF- $\beta 1$ and harvested at 7 (A-E) and $14(\mathbf{F}-\mathbf{I})$ days after injection. Asterisks indicate muscle fibers. A: Expression of RFM in blood vessels (thin arrow) and interstitial connective tissue cells (thick arrows) in the dermis and in cells interspersed among muscle fibers in the muscular layer in Ad-GFP. B-E: Increase in interstitial connective tissue cells (arrows) in the dermis (B and $\mathbf{C}$ ) and in the muscular layer ( $\mathbf{D}$ and $\mathbf{E}$ ) at 7 days. F and G: Increase in interstitial connective tissue cells (arrows) in the dermis at 14 days. $\mathbf{H}$ and $\mathbf{I}$ : Decrease in interstitial connective tissue cells (arrows) in the muscular layer in 14-day Ad-PDGF-B (H) in contrast to a persistent increase in 14-day Ad-TGF- $\beta 1$ (I). Scale bars: $100 \mu \mathrm{m}$ (A); $50 \mu \mathrm{m}$ (B-I). 
Ad-GFP
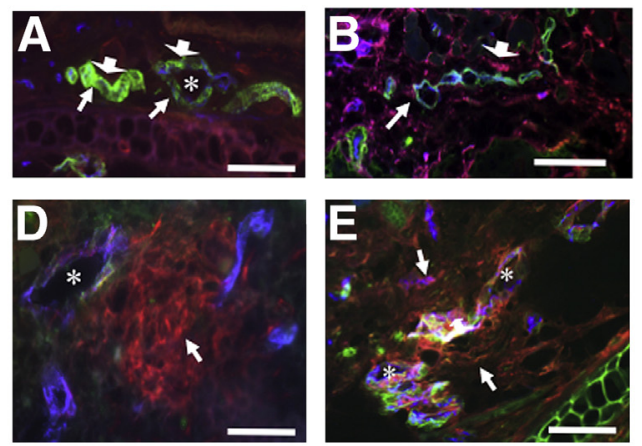

Ad-PDGF-B
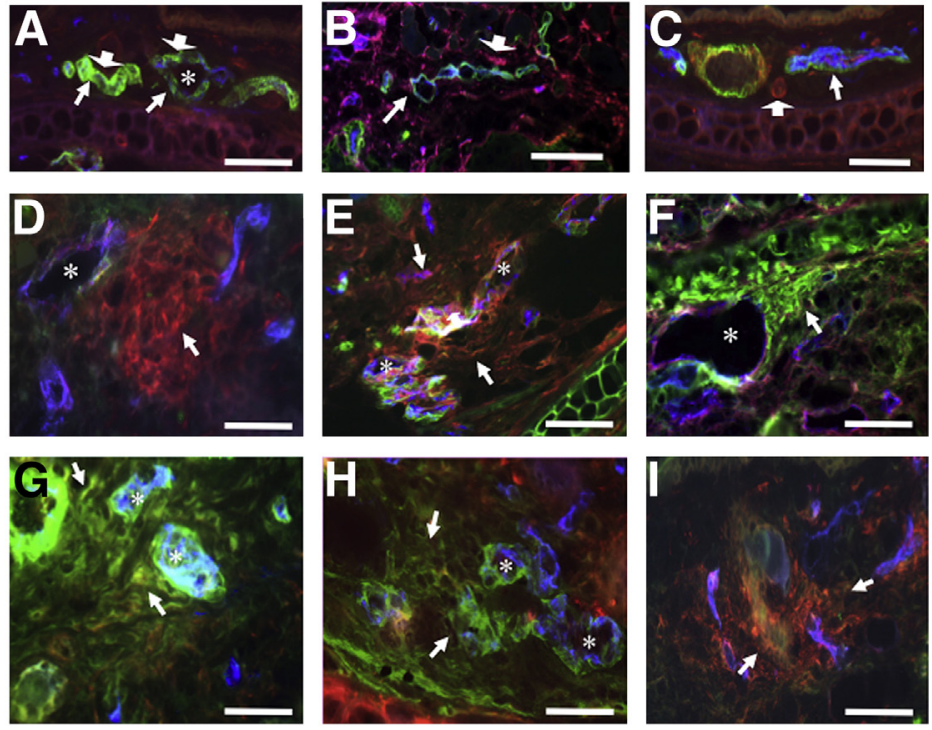

Ad-TGF- $\beta$

$\mathrm{cd} 31 / \mathrm{NG} 2(\mathrm{~J}-\mathrm{M})$
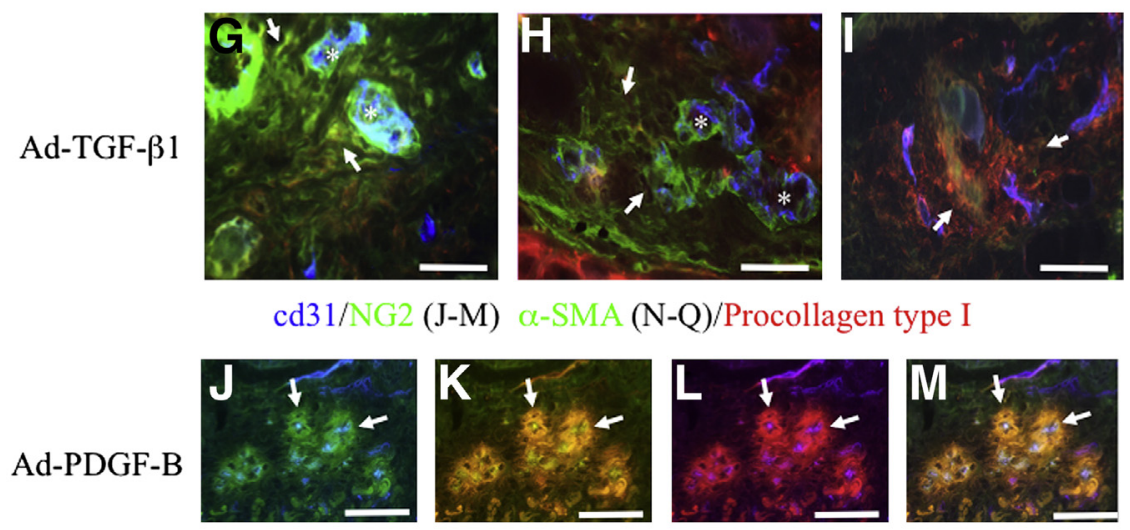

-SMA (N-Q)/Procollagen type I
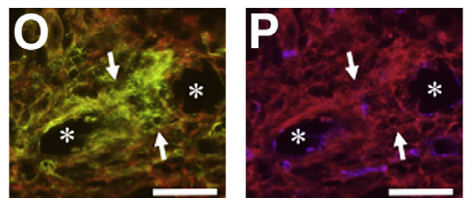
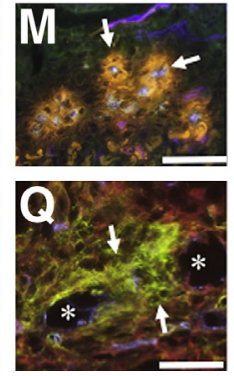

Figure 7 Diverging connective tissue cell phenotypes in Ad-PDGF-B versus Ad-TGF- $\beta 1$. Triple immunofluorescence staining in Ad-GFP, Ad-PDGF$B$, or Ad-TGF- $\beta 1$ was harvested at 7 days. Asterisks indicate blood vessels. A: $\alpha-S M A^{\text {pos }} / \mathrm{NG}^{\text {neg }}$ cells (thin arrows) are associated with PECAM- $1^{\text {pos }}$ vessels (thick arrows) in Ad-GFP. B: $\alpha-S M A^{\text {pos }}$ RFM $^{\text {pos }}$ cells (thin arrow) are associated with PECAM- $1^{\text {pos }}$ vessels and $\alpha-$ SMA $^{\text {neg }} /$ RFM $^{\text {pos }}$ cells in the interstitial space (thick arrow) in Ad-GFP. C: $N G 2^{\text {pos }} /$ RFM $^{\text {pos }}$ cells (thin arrow) are associated with PECAM- $1^{\text {pos }}$ endothelium and NG2 ${ }^{\text {neg }} /$ RFM $^{\text {pos }}$ cells in the interstitial space (thick arrow) D-F: Expansion of $\alpha-S M A^{\text {neg }} / \mathrm{NG}^{\text {pos }}$ cells (D, arrow), $\alpha-S M A^{\text {neg }} /$ RFM $^{\text {pos }}$ cells ( $E$, arrows), and NG2 ${ }^{\text {pos }} /$ RFM $^{\text {pos }}$ cells ( $F$, arrow) in the perivascular space in Ad-PDGF-B. G-I: Expansion of $\alpha-S M A^{\text {pos }} / \mathrm{NG}^{\text {neg }}$ cells (G, arrows), $\alpha-S M A^{\text {pos }} /$ RFM $^{\text {pos }}$ cells (H, arrows), and $N G 2^{\text {neg }} /$ $\mathrm{RFM}^{\text {pos }}$ cells (I, arrows) in the perivascular space in Ad-TGF- $\beta 1$. J-Q: NG $2^{\text {pos }} /$ procollagen type $\mathrm{I}^{\text {pos }}$ cells (J-M, arrows) and $\alpha-S M A^{\text {pos }} /$ procollagen type $I^{\text {pos }}$ cells $(\mathbf{N}-\mathbf{Q}$, arrows) are concentrated in the perivascular space of PECAM- $1^{\text {pos }}$ blood vessels in 7-day Ad-PDGF-B (J-M) and Ad-TGF- $\beta 1(\mathbf{N}-\mathbf{Q})$. Scale bars: $50 \mu \mathrm{m}(\mathbf{A}-\mathbf{I}) ; 100 \mu \mathrm{m}(\mathbf{J}-\mathbf{Q})$.
III (Col3a1), and V (Col5a1 and Col5a2), their modifying enzymes [lysylhydroxylase 2 (Plod2), lysyloxidase (Lox), and matrix metalloproteinase-13 (Mmp13)], as well as the scavenger receptor mannose receptor c type 2 (Mrc2) were observed in Ad-TGF- $\beta 1$ compared with Ad-GFP (Figure 9A). In Ad-PDGF, only Mrc2 mRNA was significantly increased when compared with Ad-GFP. In Ad-TGF- $\beta 1$, mRNA expression of procollagen type I and $\mathrm{V}$ and the collagen modifying enzymes Lox and Mmp13 was significantly increased compared with Ad-PDGF-B.

The collagen scaffold phenotype could also be influenced by differential expression of SLRPs and matricellular proteins (Figure 9B). The expression of mRNA for the collagen fibrilassociated SLRPs biglycan (Bgn) and fibromodulin (Fmod) was significantly increased in Ad-TGF- $\beta 1$ compared with Ad-PDGF-B and control Ad-GFP. In contrast, mRNA for two other SLRPs, lumican (Lum) and decorin (Dcn) were significantly increased in Ad-PDGF-B compared with Ad-TGF- $\beta 1$. Only Lum mRNA was significantly increased in Ad-PDGF-B compared with Ad-GFP. Of the matricellular proteins investigated, a significant increase in mRNA expression for tenascin-C (Tnc), periostin (Postn), and fibronectin (Fn) was observed in Ad-TGF- $\beta 1$ compared with Ad-GFP. Tnc and Postn mRNA expression were significantly increased in AdTGF- $\beta 1$ compared with Ad-PDGF-B. Only Fn mRNA was significantly increased in Ad-PDGF-B compared with AdGFP. The mRNA expression for the PDGF- $\beta$ receptor was significantly increased in Ad-TGF- $\beta 1$ and Ad-PDGF-B compared with Ad-GFP. The increase in the mRNA expression of PDGF- $\beta$ receptor was significantly higher in AdPDGF-B than in Ad-TGF- $\beta 1$. The mRNA expression of the TGF- $\beta$ receptor 2 and the inflammatory markers $H 2 a b 1$ (major histocompatibility complex class II subunit), IL-1 $\beta$, and S100a9 showed no significant differences in any of the three treatment groups (data not shown).

\section{Fibromodulin Expression in Ad-PDGF-B and Ad-TGF- $\beta 1$}

We were particularly interested in the SLRP Fmod because of a study from our collaborators showing that this collagenbinding proteoglycan is of central importance in determining matrix structure and fluid balance in the tumor stroma in experimental carcinomas. ${ }^{29}$ Therefore, we attempted to verify the significant increase of Fmod transcript levels in Ad-TGF- $\beta 1$ on the translational level by using immunohistochemistry (Figure 10). Protein expression levels were low in Ad-GFP (Figure 10A) and Ad-PDGF-B (Figure 10B). In adjacent unaffected skin, in Ad-TGF- $\beta 1$, low expression levels similar to Ad-GFP and Ad-PDGF-B were observed (Figure 10C). A marked increase of Fmod expression was 


\section{$\operatorname{cd} 31 / \alpha-S M A / N G 2$}

Ad-GFP
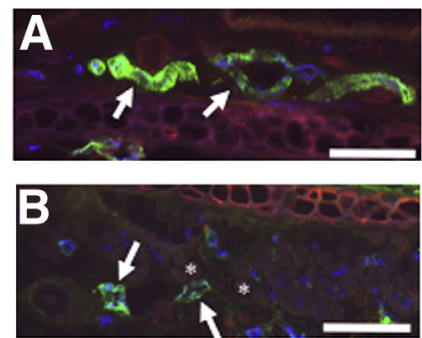

Ad-PDGF-B
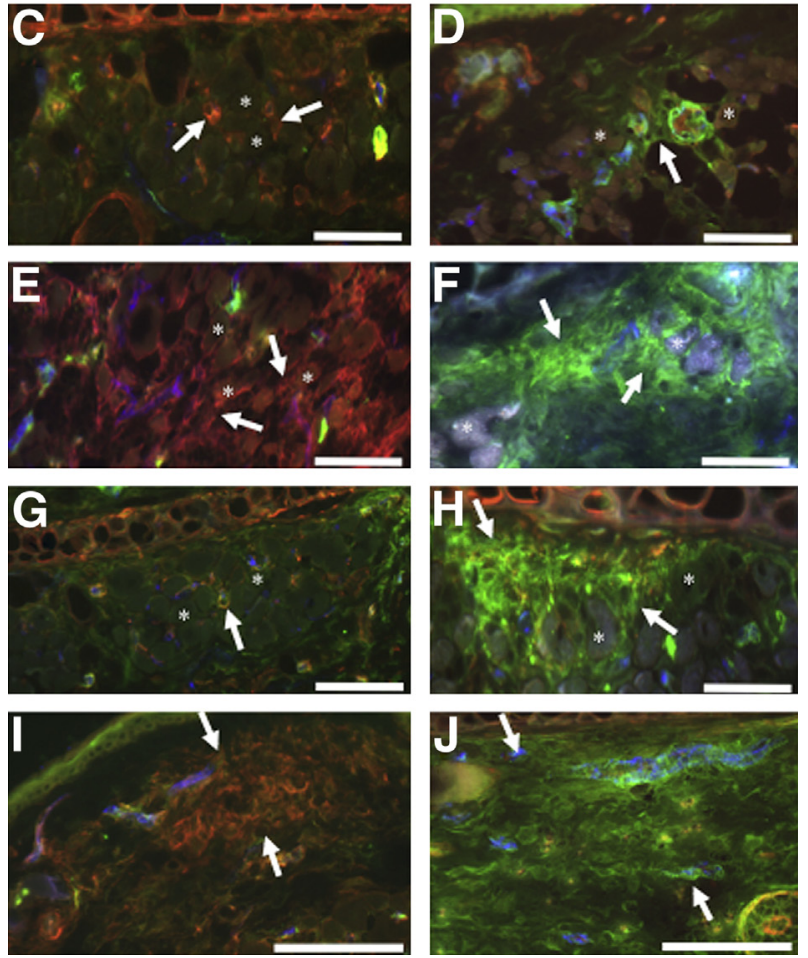

Figure 8 Temporal expansion and regression of connective tissue cell phenotypes in the subcutaneous muscular layer in Ad-PDGF-B versus Ad-TGF- $\beta 1$. Triple immunofluorescence staining in Ad-GFP, Ad-PDGF-B, and Ad-TGF- $\beta 1$ for PECAM-1 (blue) in conjunction with $\alpha$-SMA (green) and NG2 (red) at 3 days (C and $\mathbf{D}), 7$ days (A, B, E, and $\mathbf{F}$ ), and 14 days (G-J). Asterisks indicate muscle fibers. Note panels $7 \mathrm{~A}$ and $8 \mathrm{~A}$ are identical to facilitate comparison. $\mathbf{A}$ and $\mathbf{B}$ : $\alpha-S M A^{\text {pos }} /$ NG $^{\text {neg }}$ cells (arrows) are associated with PECAM- $1^{\text {pos }}$ endothelium in blood vessels in the dermis (A) and in the muscular layer (B) in Ad-GFP. $\mathbf{C}$ and $\mathbf{D}$ : Accumulations of $\alpha-S M A^{\text {neg }} / \mathrm{NG}^{\text {pos }}$ cells (C, arrows) and $\alpha-S M A^{\text {pos }} / \mathrm{NG}^{\text {neg }}$ cells (D, arrow) in the muscular layer in 3-day Ad-PDGF-B (C) and Ad-TGF- $\beta 1$ (D). E and F: Expansion of $\alpha-S M A^{\text {neg }} / \mathrm{NG}^{\text {pos }}$ cells (arrows) and $\alpha-S M A^{\text {pos }} / N G 2^{\text {neg }}$ cells (arrows) in the muscular layer in 7-day Ad-PDGF-B (E) and Ad-TGF- $\beta 1$ (F). G and $\mathbf{H}$ : Decreased cellularity with only scattered $\alpha-S M A^{\text {pos }} / \mathrm{NG}^{\text {pos }}$ cells $(\mathbf{G}$, arrow) in the muscular layer in 14-day Ad-PDGF-B. In contrast, large amounts of $\alpha-S M A^{\text {pos }} /$ NG $^{\text {neg }}$ cells persist (H, arrows) in the muscular layer in 14-day Ad-TGF- $\beta 1$. I and J: Persistence of accumulations of $\alpha-S M A^{\text {neg }} / \mathrm{NG}^{\text {pos }}$ cells (I, arrows) and $\alpha-S M A^{\text {pos }} / \mathrm{NG}^{\text {neg }}$ cells (J, arrows) in the dermis in 14-day AdPDGF-B (I) and Ad-TGF- $\beta 1$ (J). Scale bars: $50 \mu \mathrm{m}$ (A and B); $100 \mu \mathrm{m}(\mathbf{C}-\mathbf{J})$.

seen in the dermal and muscular layer in Ad-TGF- $\beta 1$ when compared with Ad-GFP and Ad-PDGF-B (Figure 10D). At a higher magnification Fmod in Ad-TGF- $\beta 1$ was predominately organized in fibrillar structures (Figure 10E).

\section{Discussion}

Angiogenesis was Initiated but Not Sustained Leading to Vascular Regression in Ad-PDGF-B and Ad-TGF- $\beta 1$

Vascular density declined in both Ad-PDGF-B and Ad-TGF- $\beta 1$. In the present study, evidence for the initial steps of angiogenesis was observed, including activation of endothelium and pericytes and the transient formation of mother vessels in both conditions. Glomeruloid bodies, that is, a structurally distinct form of angiogenesis consisting of accumulations of rapidly growing endothelial cells commonly seen in glioblastomas and in experimental animal models, ${ }^{22,27,30}$ were transiently formed in Ad-PDGF-B but not Ad-TGF- $\beta 1$. PDGF-B and TGF- $\beta 1$ could not sustain angiogenesis. The aborted angiogenesis may have led to the observed decrease in vessel
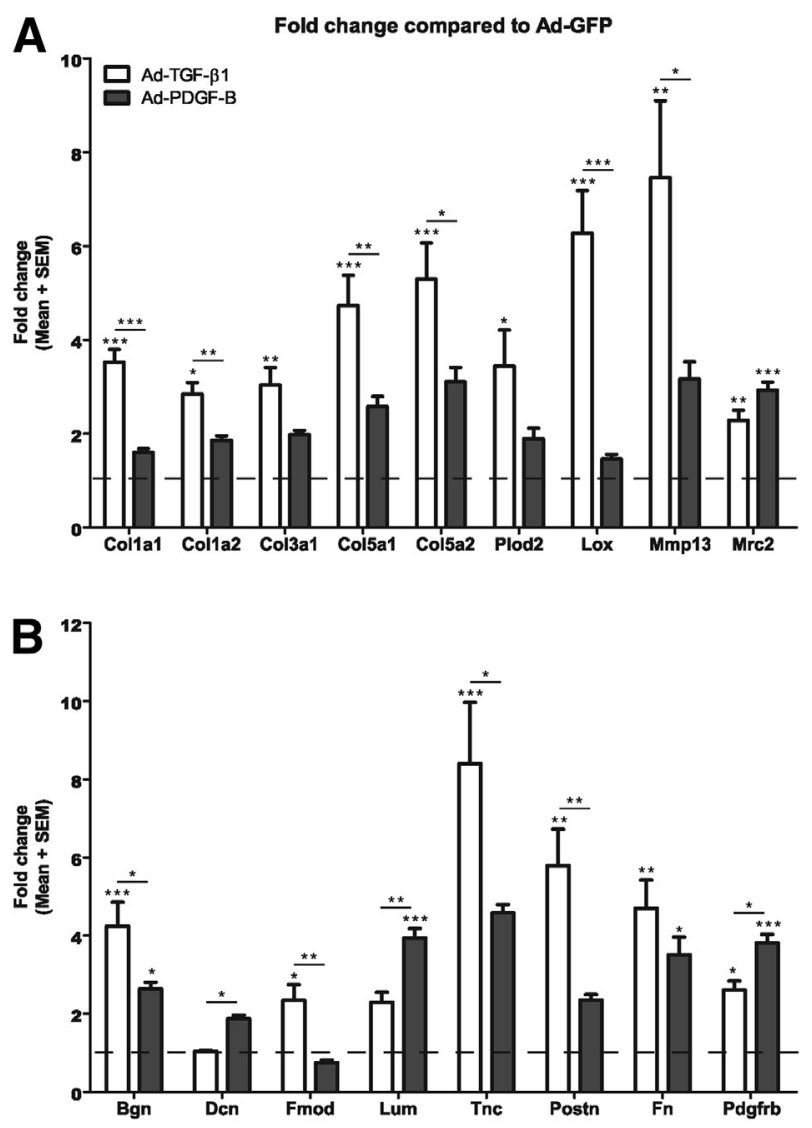

Figure 9 Differential expression levels of mRNAs in Ad-TGF- $\beta 1$ and AdPDGF-B compared with Ad-GFP. A: Fold change in mRNA coding for fibrillar procollagens, $\alpha 1$ chain of collagen I (Col1a1), III (Col3a1), and V (Col5a1); a2 chain of collagen I (Col1a2) and V (Col5a2); collagen modifying enzymes, Plod2, Lox, and Mmp-13; and the receptor for collagen degradation products, Mrc2. B: Fold change in mRNA coding for the SLRPs, Bgn, Dcn, mod, and Lum; the matricellular proteins: Tnc, Postn, and Fn; and the growth factor receptor PDGF receptor $\beta$ (Pdgfrb). Ad-GFP-induced ears served as the baseline control, and the expression of the different transcripts in these samples were set as 1 (indicated by the dotted line). ${ }^{*} P<$ $0.05,{ }^{* *} P<0.01$, and ${ }^{* *} P<0.001$. Underlined asterisks denote significant differences in levels of mRNA expression between Ad-PDGF-B and Ad-TGF- $\beta 1$. Nonunderlined asterisks denote significant differences in levels of mRNA expression compared with Ad-GFP. 

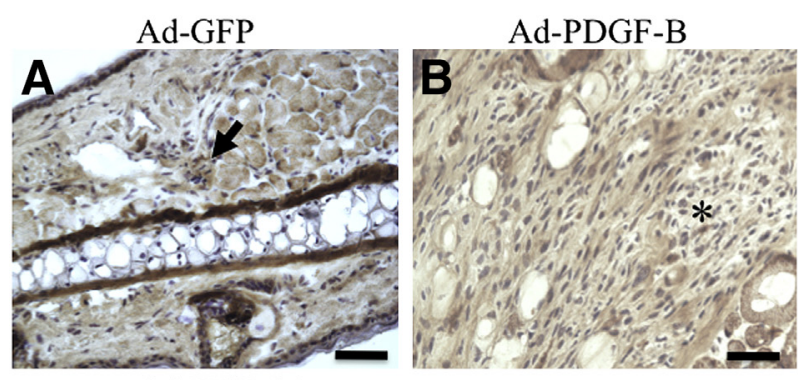

Ad-TGF- $\beta 1$

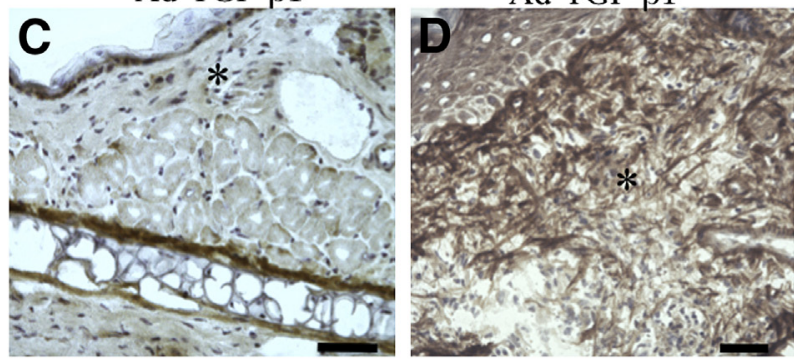

Ad-TGF- $\beta 1$

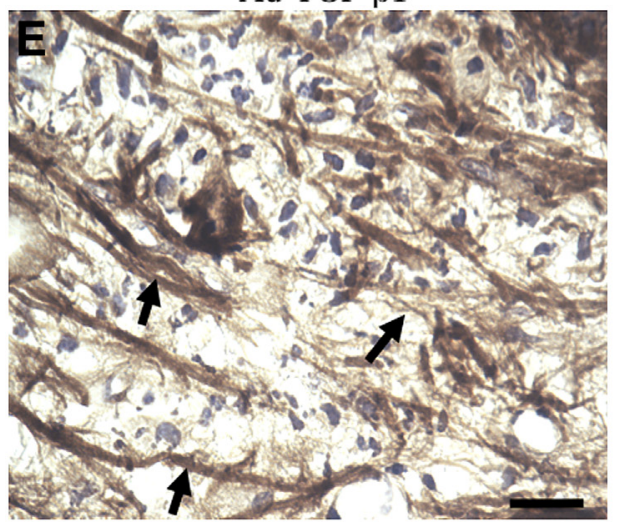

Figure 10 Expression of Fmod. Immuno-enzyme labeling with the polyclonal antibody anti-Fmod in Ad-GFP, Ad-PDGF-B, or Ad-TGF- $\beta 1$ was harvested 7 days after injection. A: Sparse expression of Fmod (arrow) in 7-day Ad-GFP (A) and in hypercellular areas in 7-day Ad-PDGF-B (B, asterisk). C-E: Lack of Fmod expression in adjacent normal tissue in 7-day Ad-TGF- $\beta 1$ (C, asterisk) in contrast to a marked expression of Fmod in the active site (D, asterisk) where at higher magnification Fmod (E, arrows) is organized in fibrilar structures. Scale bars: $100 \mu \mathrm{m}(\mathbf{A}-\mathbf{D}) ; 25 \mu \mathrm{m}(\mathbf{E})$.

density through vascular regression. This hypothesis is supported by the observed vascular-like structures that expressed $\alpha$-SMA and the basement membrane component collagen type IV but not PECAM-1. Similar structures have previously been described as vascular ghosts, that is, remnants of blood vessels that have regressed where basement membrane components and perivascular cells persist but lack an endothelial lining. ${ }^{31}$ Thus, overexpression of PDGF-B or TGF- $\beta 1$ could initiate angiogenesis, but neither could directly or indirectly sustain this process, thereby leading to partial regression of the vasculature.

Pericyte Detachment from the Endothelial Wall in Ad-PDGF-B and Ad-TGF- $\beta 1$

Both PDGF-B and TGF- $\beta 1$ have been reported to promote vessel stabilization by promoting pericyte recruitment. ${ }^{18,32}$ In the present investigation, indications of the opposite were observed. In both Ad-PDGF-B and Ad-TGF- $\beta 1$, pericytes detached from the endothelial lining and accumulated in the perivascular space. This discrepancy may be explained by the different roles that pericytes have in the neoformation of tissues during embryogenesis compared with reactive conditions in adult animals. Pericyte-endothelial cell interactions are important in stabilizing the maturing vasculature and in the regulation of vascular remodeling and regression. ${ }^{17,33,34}$ The PDGF $\beta$-receptor is expressed primarily by pericytes during embryogenesis and in a number of reactive conditions in adults. ${ }^{15,16,35-37}$ During embryogenesis in mice, PDGF-BB is important for pericyte recruitment to the microvasculature. ${ }^{17,35}$ In adult reactive tissues such as wound healing, it has been shown that mice lacking the PDGF $\beta$-receptor are deficient in their ability to generate fibroblasts. ${ }^{38}$ Thus, pericyte detachment may in part have contributed to the observed vascular regression. Taken together, our results suggest that PDGF-B and TGF- $\beta 1$ rather than being mediators of pericyte recruitment to, and stabilization of the microvasculature, have an opposite effect in adult reactive tissues leading to pericyte detachment and vessel destabilization.

Pericyte Origin of Connective Tissue Cells in Ad-PDGF-B and Ad-TGF- $\beta 1$

On the basis of structure and molecular marker expression, overexpression of PDGF-B and TGF- $\beta 1$ led to pericyte activation, detachment from the endothelial lining, and accumulation and expansion of connective tissue cells in the perivascular space. These cells expressed both pericyte and fibroblast markers. Taken together this would suggest that the emerging connective tissue cell population might originate from the microvascular pericyte. The origin of interstitial fibroblasts has long been a topic of controversy. Fibroblasts are commonly believed to be recruited from a resting fibroblast population that for instance in wound healing reside in the adjacent normal tissue. ${ }^{3,39}$ Other studies suggest an epithelial-mesenchymal and/or endothelial-mesenchymal transition as a source of fibroblasts. ${ }^{40}$ In the former case, it is believed that TGF- $\beta 1$ plays an important role in that transition. ${ }^{40}$ Yet other studies suggest a bone marrow-derived origin of fibroblasts, that is, fibrocytes. ${ }^{5} \mathrm{We}$ and others have put forth a hypothesis that microvascular pericytes serve as progenitor cells for fibroblasts/myofibroblasts during tissue repair and human pathologies characterized by fibrosis. ${ }^{15,16,28,37,38,41-45}$ The present results support that both PDGF-B and TGF- $\beta 1$ play an important role in the generation and expansion of fibroblasts that may originate from a subset of microvascular pericytes.

\section{Divergent Connective Tissue Cell Phenotypes in Ad-PDGF-B Compared with Ad-TGF- $\beta 1$}

Emerging connective tissue cell populations phenotypically differed between Ad-TGF- $\beta 1$ and Ad-PDGF-B. Pericytes 
express $\alpha$-SMA in several but not all resting tissues. ${ }^{3,39}$ On activation in wound healing and tumor progression, $\alpha$-SMA is downregulated in pericytes that instead begin to express the pericyte activation marker high molecular weight melanoma-associated antigen, ${ }^{16,46}$ which is the human equivalent to NG2 in the mouse. The emergence of $\alpha$-SMAexpressing connective tissue cells, that is, myofibroblasts, occurs in a number of pathological conditions in the adult animal as well as tissue reparative processes. ${ }^{3,39,47}$ Myofibroblasts are of central importance in the fibrotic process through neosynthesis and organization of collagen type I and other matrix components. ${ }^{3,39}$ The transition of connective tissue cells into the myofibroblast phenotype is governed by several factors, including the ability to adhere to the surrounding ECM as well as exposure to growth factors such as TGF- $\beta 1{ }^{3,28}$ Ad-TGF- $\beta 1$ but not Ad-PDGF-B resulted in the emergence of a connective tissue cell population that was consistent with the myofibroblast phenotype. In contrast, overexpression of PDGF-B generated a $\alpha$-SMA-negative fibroblast population that expressed the pericyte activation marker NG2. Thus, PDGF-B resulted in the emergence of a connective tissue cell population that, based on the marker expression, remained more pericyte-like but was not capable of inducing the myofibroblast phenotype. Despite the lack of myofibroblasts in Ad-PDGF-B, neosynthesis of collagen type I did occur, suggesting that this phenotypical transition is not an absolute prerequisite for neosynthesis to occur. The results show that PDGF-B and TGF- $\beta 1$ have different effects on the propagation and differentiation of connective tissue cells in vivo.

\section{Partial Reversibility of the Effects in Ad-PDGF-B Compared with Ad-TGF- $\beta 1$}

In the present study, the increase in connective tissue cells and infiltration of inflammatory cells regressed in the muscular layer in Ad-PDGF-B but not Ad-TGF- $\beta 1$. Inflammation and the fibrotic process are closely interconnected. ${ }^{5}$ However, the amount of fibrosis is not always linked to the severity of inflammation, indicating mechanisms in part distinct from those that regulate inflammation and the development of fibrosis. ${ }^{5}$ One explanation might lie in local differences in the inflammatory reaction. However, a seemingly equal amount of macrophage infiltration was present in both the dermal and muscular compartments in both conditions. Furthermore, no differences in mRNAs coding for the inflammatory markers H2ab1 (major histocompatibility complex class II subunit), IL-1 $\beta$, or S100a9 were observed (data not shown). One other explanation might be in the observed differences in the emerging connective tissue cell phenotypes between the dermis and the muscle layer in Ad-PDGF-B. However, no such differences in the expression of the markers used in this study were observed. One possibility is that these cells were derived from different populations of precursor cells. ${ }^{39}$ Although our results suggest the microvascular pericyte as a common origin for the emerging connective tissue cell populations in response to overexpression of PDGF-B and TGF- $\beta 1$, differences in the microvascular pericyte phenotype between the dermal and muscular layer may exist. It has previously been shown that heterogeneity of fibrogenic cells between tissues but also within the same tissue exist. ${ }^{3,48,49}$ For instance, in the liver, phenotypically divergent fibrogenic cells are derived from different spatially distinct populations of precursor cells which respond differently to individual cytokines. ${ }^{50-52}$ In the liver, a distinct population of periportal cells undergoes a PDGF-BB-dependent conversion to a profibrotic phenotype distinct from myofibroblasts in septal fibrosis. ${ }^{53}$ The reversibility in the muscular layer in AdPDGF-B but not in the Ad-TGF- $\beta 1$ suggests differences that may potentially be exploited to reduce or eventually even reverse the fibrotic process with the use of selective inhibitors of growth factors and their receptors. Further studies are required to resolve this issue.

\section{Effects on mRNA Expression of Extracellular Matrix Components and Their Modifiers in Ad-PDGF-B and Ad-TGF- $\beta 1$}

The observed differences in connective tissue cell phenotype were also reflected in the expression of mRNA of fibrillar collagens as well as modifying enzymes and cofactors that influence collagen assembly and organization. ${ }^{54}$ The mRNA levels of two important collagen-modifying enzymes, Plod2 and Lox, were increased in Ad-TGF- $\beta 1$ compared with AdPDGF-B and control Ad-GFP. Plod2 is essential for the stability of the intermolecular collagen crosslinks between collagen monomers. Lox catalyzes mature trivalent covalent crosslinks between the collagen monomers, thereby further stabilizing and conferring strength to the collagen fibril. ${ }^{55,56}$ The SLRPs bind to fibrillar collagens and regulate collagen fibril thickness, assembly, and structure by regulating the fusion of thinner collagen fibril intermediates into larger fibrils. ${ }^{7}$ The mRNA expression levels of the SLRPs Bgn and Fmod were elevated in Ad-TGF- $\beta 1$ compared with AdPDGF-B and control Ad-GFP. Fmod enhances lateral fusion of collagen fibrils, resulting in thicker fibrils, but also protects collagens from enzymatic degradation by, for example, Mmp13, which on the mRNA level was upregulated in Ad-TGF- $\beta 1{ }^{57}$ Furthermore, Fmod stabilizes ECM structure and thereby is important in the maintenance of mature tissues. ${ }^{29,58}$ Both Bgn and Fmod have been reported to increase in fibrotic processes such as bleomycin-induced lung fibrosis. ${ }^{59}$ This occurs concomitant with an increased expression of TGF- $\beta 1$ and collagen type III. ${ }^{60}$ The increased expression of mRNA coding for the matricellular proteins Tnc and Postn in Ad-TGF- $\beta 1$ was not surprising because it has been shown that TGF- $\beta 1$ is a potent inducer of both proteins in fibrotic conditions. ${ }^{61}$ The expression of the matricellular proteins is often increased during embryogenesis and in conditions in which active tissue remodeling is occurring. One function of these matricellular proteins are 
to render cells more mobile and to alter their phenotype, thereby increasing the ability of cells to migrate and reorganize the ECM microenvironment. ${ }^{62,63}$ In addition to being a ligand for adhesion receptors, Postn also affects the thickness of collagen fibers. ${ }^{64}$ Taken together, overexpression of TGF- $\beta 1$ not only results in a quantitative increase in ECM deposition but also affects the quality of the ECM and its assembly on the molecular level, which would lead to and maintain a denser collagen scaffold.

The present results show a trend toward increased expression of mRNAs coding for fibrillar procollagens in AdPDGF-B, but the differences did not reach statistical significance. Increased expression of procollagen type I protein was observed in Ad-PDGF-B as well as Ad-TGF- $\beta 1$ compared with Ad-GFP. It has previously been shown for collagen type I that changes in mRNA levels do not necessarily translate into changes in protein levels. ${ }^{54,65}$ Thus, PDGF may have an effect on the translational rather than the transcriptional level in collagen synthesis. An alternative explanation is that procollagen type I protein expression was evenly dispersed in tissues in Ad-TGF- $\beta 1$, whereas expression in Ad-PDGF-B was primarily concentrated to the perivascular space. Thus, local hotspots of increased collagen synthesis may not suffice to significantly alter the total amount of mRNA for collagens measured in the Ad-PDGF-B tissue samples.

The expression of the SLRPs Lum and Den mRNA was increased in Ad-PDGF-B compared with Ad-TGF- $\beta 1$. These two proteins facilitate the formation of thinner collagen fibrils by inhibiting excess lateral fusion of collagen fibrils, thereby limiting their growth. Both Lum and Den are downregulated as fibrotic responses progress. ${ }^{7}$ The consequence of increased mRNA levels of Lum and Den in AdPDGF-B might be to control the size of collagen fibrils to inhibit the formation of a dense collagen scaffold. A less dense scaffold would facilitate remodeling, which would favor a nonfibrotic outcome of the Ad-PDGF-B-induced lesion. This is further supported by the lack of upregulation of Fmod in Ad-PDGF-B. Lum affects early stages, whereas Fmod has an effect on the later stages of collagen fibrillogenesis. ${ }^{58}$ This is consistent with the observation that Lum expression precedes expression of Fmod in wound-healing models. ${ }^{58}$ Moreover, the observed increased expression of Mrc2 mRNA in Ad-PDGF-B would enhance collagen scaffold remodeling and recycling of non-cross-linked collagen monomers. ${ }^{66} \mathrm{Fn}$ is expressed early on during the formation of granulation tissue and was overexpressed in Ad-PDGF-B. ${ }^{66}$ Taken together, overexpression of PDGF-B leads to a less dense collagen scaffold and results in changes reminiscent of granulation tissue and immature scars where active ECM remodeling more easily occurs. ${ }^{66}$

The alterations in the mRNA profile of the molecules studied in this investigation in response to overexpression of TGF- $\beta 1$ may lead to the formation of a denser ECM, consistent with what is seen in advanced fibrotic conditions. The alterations in the mRNA profile in response to overexpression of PDGF-B suggest the formation of an ECM microenvironment more consistent with immature granulation tissue, a condition that proceeds but does not necessarily lead to the development of fibrosis. The consequence of the differences seen in Ad-TGF$\beta 1$ compared with Ad-PDGF-B may be the formation of a rigid, tensile, and stiffer matrix in Ad-TGF- $\beta 1$. These characteristics would influence cell migration, cell differentiation, interstitial fluid pressure, drug delivery, and progression of fibrosis and would promote the malignant phenotype in solid tumors. ${ }^{6,67-69}$

\section{Conclusion}

In conclusion, this study offers new insight into the in vivo effects of PDGF-B and TGF- $\beta 1$ and offers potentially new therapeutic targets aimed at perturbing or reversing the process of tissue fibrosis as well as promoting optimal tissue regeneration.

\section{Acknowledgment}

We thank Anders Ahlander for providing excellent technical support.

\section{References}

1. Folkman J: Asngiogenesis in cancer, vascular, rheumatoid and other disease. Nat Med 1995, 1:27-31

2. Dvorak HF: Tumors: wounds that do not heal. Similarities between tumor stroma generation and wound healing. N Engl J Med 1986, 315:1650-1659

3. Gabbiani G: The myofibroblast in wound healing and fibrocontractive diseases. J Pathol 2003, 200:500-503

4. Hinz B, Phan SH, Thannickal VJ, Prunotto M, Desmouliere A, Varga J, De Wever O, Mareel M, Gabbiani G: Recent developments in myofibroblast biology: paradigms for connective tissue remodeling. Am J Pathol 2012, 180:1340-1355

5. Wynn TA: Cellular and molecular mechanisms of fibrosis. J Pathol 2008, 214:199-210

6. Reed RK, Liden A, Rubin K: Edema and fluid dynamics in connective tissue remodelling. J Mol Cell Cardiol 2010, 48:518-523

7. Kalamajski S, Oldberg A: The role of small leucine-rich proteoglycans in collagen fibrillogenesis. Matrix Biol 2010, 29: 248-253

8. Yang GP, Lim IJ, Phan TT, Lorenz HP, Longaker MT: From scarless fetal wounds to keloids: molecular studies in wound healing. Wound Repair Regen 2003, 11:411-418

9. Lasky JA, Brody AR: Interstitial fibrosis and growth factors. Environ Health Perspect 2000, 108(Suppl 4):751-762

10. Margadant $\mathrm{C}$, Sonnenberg A: Integrin-TGF- $\beta$ crosstalk in fibrosis, cancer and wound healing. EMBO Rep 2010, 11:97-105

11. Trojanowska M: Role of PDGF in fibrotic diseases and systemic sclerosis. Rheumatology (Oxford) 2008, 47(Suppl 5):v2-v4

12. Pohlers D, Brenmoehl J, Loffler I, Muller CK, Leipner C, SchultzeMosgau S, Stallmach A, Kinne RW, Wolf G: TGF- $\beta$ and fibrosis in different organs - molecular pathway imprints. Biochim Biophys Acta 2009, 1792:746-756

13. Kim KK, Kugler MC, Wolters PJ, Robillard L, Galvez MG, Brumwell AN, Sheppard D, Chapman HA: Alveolar epithelial cell mesenchymal transition develops in vivo during pulmonary fibrosis and is regulated by the extracellular matrix. Proc Natl Acad Sci U S A 2006, 103:13180-13185 
14. Czochra P, Klopcic B, Meyer E, Herkel J, Garcia-Lazaro JF, Thieringer F, Schirmacher P, Biesterfeld S, Galle PR, Lohse AW, Kanzler S: Liver fibrosis induced by hepatic overexpression of PDGF-B in transgenic mice. J Hepatol 2006, 45:419-428

15. Rajkumar VS, Sundberg C, Abraham DJ, Rubin K, Black CM: Activation of microvascular pericytes in autoimmune Raynaud's and systemic sclerosis. Arthritis Rheum 1999, 42:930-941

16. Sundberg C, Ljungstrom M, Lindmark G, Gerdin B, Rubin K: Microvascular pericytes express platelet-derived growth factor$\beta$ receptors in human healing wounds and colorectal adenocarcinoma. Am J Pathol 1993, 143:1377-1388

17. Armulik A, Abramsson A, Betsholtz C: Endothelial/pericyte interactions. Circ Res 2005, 97:512-523

18. Goumans MJ, Liu Z, ten Dijke P: TGF- $\beta$ signaling in vascular biology and dysfunction. Cell Res 2009, 19:116-127

19. Korpisalo P, Karvinen H, Rissanen TT, Kilpijoki J, Marjomaki V, Baluk P, McDonald DM, Cao Y, Eriksson U, Alitalo K, Yla-Herttuala S: Vascular endothelial growth factor-A and platelet-derived growth factor-B combination gene therapy prolongs angiogenic effects via recruitment of interstitial mononuclear cells and paracrine effects rather than improved pericyte coverage of angiogenic vessels. Circ Res 2008, 103:1092-1099

20. Brunner AM, Marquardt H, Malacko AR, Lioubin MN, Purchio AF: Site-directed mutagenesis of cysteine residues in the pro region of the transforming growth factor $\beta 1$ precursor. Expression and characterization of mutant proteins J Biol Chem 1989, 264:13660-13664

21. Abe M, Harpel JG, Metz CN, Nunes I, Loskutoff DJ, Rifkin DB: An assay for transforming growth factor- $\beta$ using cells transfected with a plasminogen activator inhibitor-1 promoter-luciferase construct. Anal Biochem 1994, 216:276-284

22. Sundberg C, Nagy JA, Brown LF, Feng D, Eckelhoefer IA, Manseau EJ, Dvorak AM, Dvorak HF: Glomeruloid microvascular proliferation follows adenoviral vascular permeability factor/vascular endothelial growth factor-164 gene delivery. Am J Path 2001, 158 : $1145-1160$

23. Skalli O, Ropraz P, Trzeciak A, Benzonona G, Gilessen D, Gabbiani G: A monoclonal antibody against $\alpha$-smooth muscle actin: a new probe for smooth muscle differentiation. J Cell Biol 1986, 103: 2787-2796

24. Van Muijen GN, Ruiter DJ, Warnaar SO: Co-expression of intermediate filament polypeptides in human fetal and adult tissues. Lab Invest 1987, 57:359-369

25. Schlingemann RO, Rietveld FJR, de Waal RMW, Ferrone S, Ruiter DJ: Expression of the high molecular weight-melanoma associated antigen by pericytes during angiogenesis in tumors and in healing wounds. Am J Path 1990, 136:1393-1405

26. Svensson L, Aszodi A, Reinholt FP, Fassler R, Heinegard D, Oldberg A: Fibromodulin-null mice have abnormal collagen fibrils, tissue organization, and altered lumican deposition in tendon. J Biol Chem 1999, 274:9636-9647

27. Pettersson A, Nagy JA, Brown LF, Sundberg C, Morgan E, Jungles S, Carter R, Krieger JE, Manseau EJ, Harvey VS, Eckelhoefer IA, Feng D, Dvorak AM, Mulligan RC, Dvorak HF: Heterogeneity of the angiogenic response induced in different normal adult tissues by vascular permeability factor/vascular endothelial growth factor. Lab Invest 2000, 80:99-115

28. Rodriguez A, Karen J, Gardner H, Gerdin B, Rubin K, Sundberg C: Integrin $\alpha 1 \beta 1$ is involved in the differentiation into myofibroblasts in adult reactive tissues in vivo. J Cell Mol Med 2009, 13:3449-3462

29. Oldberg A, Kalamajski S, Salnikov AV, Stuhr L, Morgelin M, Reed RK, Heldin NE, Rubin K: Collagen-binding proteoglycan fibromodulin can determine stroma matrix structure and fluid balance in experimental carcinoma. Proc Natl Acad Sci U S A 2007, 104: 13966-13971

30. Brat DJ, Mapstone TB: Malignant glioma physiology: cellular response to hypoxia and its role in tumor progression. Ann Intern Med 2003, 138:659-668
31. Inai $T$, Mancuso $M$, Hashizume $H$, Baffert $F$, Haskell A, Baluk $P$, Hu-Lowe DD, Shalinsky DR, Thurston G, Yancopoulos GD, McDonald DM: Inhibition of vascular endothelial growth factor (VEGF) signaling in cancer causes loss of endothelial fenestrations, regression of tumor vessels, and appearance of basement membrane ghosts. Am J Pathol 2004, 165:35-52

32. Gaengel K, Genove G, Armulik A, Betsholtz C: Endothelial-mural cell signaling in vascular development and angiogenesis. Arterioscler Thromb Vasc Biol 2009, 29:630-638

33. Benjamin LE, Hemo I, Keshet E: A plasticity window for blood vessel remodelling is defined by pericyte coverage of the preformed endothelial network and is regulated by PDGF-B and VEGF. Development 1998, 125:1591-1598

34. Benjamin L, Golijanin D, Itin A, Pode D, Keshet E: Selective ablation of immature blood vessels in established human tumors follows vascular endothelial growth factor withdrawal. J Clin Invest 1999, 103:159-165

35. Lindahl P, Johansson BR, Levéen P, Betscholtz C: Pericyte loss and microaneurysm formation in PDGF B-chain deficient mice. Science 1997, 277:242-245

36. Sundberg C, Friman T, Hecht LE, Kuhl C, Solomon KR: Two different PDGF $\beta$-receptor cohorts in human pericytes mediate distinct biological endpoints. Am J Pathol 2009, 175:171-189

37. Sundberg C, Branting M, Gerdin B, Rubin K: Tumor cell and connective tissue cell interactions in human colorectal adenocarcinoma: transfer of platelet-derived growth factor $\mathrm{AB} / \mathrm{BB}$ to stromal cells. Am J Path 1997, 151:479-492

38. Crosby JR, Tappan KA, Seifert RA, Bowen-Pope DF: Chimeric analysis reveals that fibroblasts and endothelial cells require plateletderived growth factor receptor $\beta$ expression for participation in reactive connective tissue formation in adults but not during development. Am J Pathol 1999, 154:1315-1321

39. Desmouliere A, Guyot C, Gabbiani G: The stroma reaction myofibroblast: a key player in the control of tumor cell behavior. Int J Dev Biol 2004, 48:509-517

40. Darby IA, Hewitson TD: Fibroblast differentiation in wound healing and fibrosis. Int Rev Cytol 2007, 257:143-179

41. Ivarsson M, Sundberg C, Farrokhnia N, Pertoft H, Rubin K, Gerdin B: Recruitment of type I collagen producing cells from the microvasculature in vitro. Exp Cell Res 1996, 229:336-349

42. Sundberg C, Ivarsson M, Gerdin B, Rubin K: Pericytes as collagen producing cells in excessive dermal scarring. Lab Invest 1996, 74: 452-466

43. Sundberg C, Kowanetz M, Brown LF, Detmar M, Dvorak HF: Stable expression of angiopoietin-1 and other markers by cultured pericytes: phenotypic similarities to a subpopulation of cells in maturing vessels during later stages of angiogenesis in vivo. Lab Invest 2002, 82: 387-401

44. Ronnov-Jessen L, Petersen OW, Koteliansky VE, Bissel MJ: The origin of myofibroblasts in breast cancer. J Clin Invest 1995, 95: 859-873

45. Lin SL, Kisseleva T, Brenner DA, Duffield JS: Pericytes and perivascular fibroblasts are the primary source of collagen-producing cells in obstructive fibrosis of the kidney. Am J Pathol 2008, 173: $1617-1627$

46. Schlingemann RO, Rietveld FJR, Kwaspen F, van der Kerkhof FPC, de Waal MW, Ruiter DJ: Differential expression of markers for endothelial cells, pericytes and basal lamina in the microvasculature of tumors and granulation tissue. Am J Path 1991, 138:1335-1347

47. Skalli O, Pelte MF, Peclet MC, Gabbiani G, Gugliotta P, Bussolati G, Ravazzola M, Orci L: $\alpha$-Smooth muscle actin, a differentiation marker of smooth muscle cells, is present in microfilamentous bundles of pericytes. J Histochem Cytochem 1989, 37:315-321

48. Sappino AP, Schurch W, Gabbiani G: Differentiation repertoire of fibroblastic cells: expression of cytoskeletal proteins as marker of phenotypic modulations. Lab Invest 1990, 63:144-161 
49. Skalli O, Schurch W, Seemayer T, Lagace R, Montandon D, Pittet B, Gabbiani G: Myofibroblasts from diverse pathologic settings are heterogeneous in their content of actin isoforms and intermediate filament proteins. Lab Invest 1989, 60:275-285

50. Tuchweber B, Desmouliere A, Bochaton-Piallat ML, RubbiaBrandt L, Gabbiani G: Proliferation and phenotypic modulation of portal fibroblasts in the early stages of cholestatic fibrosis in the rat. Lab Invest 1996, 74:265-278

51. Kinnman N, Francoz C, Barbu V, Wendum D, Rey C, Hultcrantz R, Poupon R, Housset C: The myofibroblastic conversion of peribiliary fibrogenic cells distinct from hepatic stellate cells is stimulated by platelet-derived growth factor during liver fibrogenesis. Lab Invest 2003, 83:163-173

52. Hinz B, Gabbiani G: Cell-matrix and cell-cell contacts of myofibroblasts: role in connective tissue remodeling. Thromb Haemost 2003, 90:993-1002

53. Shao ZM, Nguyen M, Barsky SH: Human breast carcinoma desmoplasia is PDGF initiated. Oncogene 2000, 19:4337-4345

54. Ghosh AK: Factors involved in the regulation of type I collagen gene expression: implication in fibrosis. Exp Biol Med (Maywood) 2002, 227:301-314

55. Bailey AJ, Paul RG, Knott L: Mechanisms of maturation and ageing of collagen. Mech Ageing Dev 1998, 106:1-56

56. Eyre DR, Weis MA, Wu JJ: Advances in collagen cross-link analysis. Methods 2008, 45:65-74

57. Geng Y, McQuillan D, Roughley PJ: SLRP interaction can protect collagen fibrils from cleavage by collagenases. Matrix Biol 2006, 25 : 484-491

58. Chakravarti S: Functions of lumican and fibromodulin: lessons from knockout mice. Glycoconj J 2002, 19:287-293

59. Venkatesan N, Ebihara T, Roughley PJ, Ludwig MS: Alterations in large and small proteoglycans in bleomycin-induced pulmonary fibrosis in rats. Am J Respir Crit Care Med 2000, 161: 2066-2073

60. Westergren-Thorsson G, Hernnas J, Sarnstrand B, Oldberg A, Heinegard D, Malmstrom A: Altered expression of small proteoglycans, collagen, and transforming growth factor- $\beta 1$ in developing bleomycin-induced pulmonary fibrosis in rats. J Clin Invest 1993, 92 : 632-637

61. Kudo A: Periostin in fibrillogenesis for tissue regeneration: periostin actions inside and outside the cell. Cell Mol Life Sci 2011, 68: 3201-3207

62. Midwood KS, Williams LV, Schwarzbauer JE: Tissue repair and the dynamics of the extracellular matrix. Int J Biochem Cell Biol 2004, 36:1031-1037

63. Chung CY, Murphy-Ullrich JE, Erickson HP: Mitogenesis, cell migration, and loss of focal adhesions induced by tenascin-C interacting with its cell surface receptor, annexin II. Mol Biol Cell 1996, 7 : 883-892

64. Norris RA, Damon B, Mironov V, Kasyanov V, Ramamurthi A, Moreno-Rodriguez R, Trusk T, Potts JD, Goodwin RL, Davis J, Hoffman S, Wen X, Sugi Y, Kern CB, Mjaatvedt CH, Turner DK, Oka T, Conway SJ, Molkentin JD, Forgacs G, Markwald RR: Periostin regulates collagen fibrillogenesis and the biomechanical properties of connective tissues. J Cell Biochem 2007, 101:695-711

65. Dahlman T, Lammerts E, Bergstrom D, Franzen A, Westermark K, Heldin NE, Rubin K: Collagen type I expression in experimental anaplastic thyroid carcinoma: regulation and relevance for tumorigenicity. Int J Cancer 2002, 98:186-192

66. Kurkinen M, Vaheri A, Roberts PJ, Stenman S: Sequential appearance of fibronectin and collagen in experimental granulation tissue. Lab Invest 1980, 43:47-51

67. Yeung T, Georges PC, Flanagan LA, Marg B, Ortiz M, Funaki M, Zahir N, Ming W, Weaver V, Janmey PA: Effects of substrate stiffness on cell morphology, cytoskeletal structure, and adhesion. Cell Motil Cytoskeleton 2005, 60:24-34

68. Georges PC, Hui JJ, Gombos Z, McCormick ME, Wang AY, Uemura M, Mick R, Janmey PA, Furth EE, Wells RG: Increased stiffness of the rat liver precedes matrix deposition: implications for fibrosis. Am J Physiol Gastrointest Liver Physiol 2007, 293 G1147-G1154

69. Heldin $\mathrm{CH}$, Rubin K, Pietras K, Ostman A: High interstitial fluid pressure - an obstacle in cancer therapy. Nat Rev Cancer 2004, 4: 806-813 